\title{
Clinical Guidelines for Drug-Related Peptic Ulcer, 2020 Revised Edition
}

Moon Kyung Joo ${ }^{1}$, Chan Hyuk Park ${ }^{2}$, Joon Sung Kim³ ${ }^{3}$, Jae Myung Park ${ }^{4}$, Ji Yong Ahn ${ }^{5}$, Bong Eun Lee ${ }^{6}$, Jeong Hoon Lee ${ }^{5}$, Hyo-Joon Yang ${ }^{7}$, Yu Kyung $\mathrm{Cho}^{4}$, Chang Seok Bang ${ }^{8}$, Beom Jin Kim ${ }^{9}$, Hye-Kyung Jung ${ }^{10}$, Byung-Wook Kim ${ }^{3}$, and Yong Chan Lee $^{11}$, Korean College of Helicobacter and Upper Gastrointestinal Research

${ }^{1}$ Department of Internal Medicine, Korea University Guro Hospital, Korea University College of Medicine, Seoul, ${ }^{2}$ Department of Internal Medicine, Hanyang University Guri Hospital, Hanyang University College of Medicine, Guri, ${ }^{3}$ Department of Internal Medicine, Incheon St. Mary's Hospital, College of Medicine, The Catholic University of Korea, ${ }^{4}$ Department of Internal Medicine, Seoul St. Mary's Hospital, College of Medicine, The Catholic University of Korea, ${ }^{5}$ Department of Gastroenterology, Asan Medical Center, Asan Digestive Disease Research Institute, University of Ulsan College of Medicine, Seoul, ${ }^{6}$ Departments of Internal Medicine, Pusan National University School of Medicine, Busan, ${ }^{7}$ Division of Gastroenterology, Department of Internal Medicine, Kangbuk Samsung Hospital, Sungkyunkwan University School of Medicine, Seoul, ${ }^{8}$ Department of Internal Medicine, Hallym University College of Medicine, Chuncheon, ${ }^{9}$ Department of Internal Medicine, Chung-Ang University College of Medicine, ${ }^{10}$ Department of Internal Medicine, Ewha Womans University College of Medicine, and ${ }^{11}$ Department of Internal Medicine, Yonsei University College of Medicine, Seoul, Korea

Korean guidelines for nonsteroidal anti-inflammatory drug (NSAID)-induced peptic ulcer were previously developed in 2009 with the collaboration of the Korean College of Helicobacter and Upper Gastrointestinal Research and Korean Society of Gastroenterology. However, the previous guidelines were based mainly upon a review of the relevant literature and expert opinion. Therefore, the guidelines need to be revised. We organized a guideline Development Committee for drug-related peptic ulcer under the auspices of the Korean College of Helicobacter and Upper Gastrointestinal Research in 2017 and developed nine statements, including four for NSAIDs, three for aspirin and other antiplatelet agents, and two for anticoagulants through a de novo process founded on evidence-based medicine that included a literature search and a meta-analysis, A consensus was reached through the application of the modified Delphi method. The primary target of these guidelines is adult patients undergoing long-term treatment with NSAIDs, aspirin or other antiplatelet agents and anticoagulants. The revised guidelines reflect the expert consensus and is intended to assist clinicians in the management and prevention of druginduced peptic ulcer and associated conditions. (Gut Liver 2020;14:707-726)

Key Words: Peptic ulcer; Non-steroidal anti-inflammatory agents; Antiplatelet agent; Anticoagulants; Guideline

\section{INTRODUCTION}

Korea has the world's most rapidly aging population, and the prevalence of chronic diseases like osteoarthritis or cerebrovascular diseases and the corresponding financial burden on individuals and society are increasing rapidly. ${ }^{1,2}$ Furthermore, as nonsteroidal anti-inflammatory drugs (NSAIDs), aspirin or other antiplatelet agents or anticoagulants continue to be used as a primary therapeutic agent for chronic diseases, primary care physicians frequently experience drug-induced gastrointestinal (GI) side effects. These include GI damage such as peptic ulcer (PU) or bleeding. ${ }^{3}$ Previous large-scale randomized control studies showed that the annual incidence of upper GI clinical events, which included uncomplicated symptomatic PU, by use of nonselective NSAID ranged from $2.7 \%$ to $4.5 \%$, and that of major complications such as bleeding or perforation ranged from 1.0\% to $1.5 \%,{ }^{4-7}$ and other pivotal studies have shown that aspirin is the most potent risk factor for GI bleeding when combined with other antiplatelet agents, such as clopidogrel..$^{8,9}$ A previous Korean multicenter cohort study showed that prevalence of Helicobacter pylori infection in Korea decreased significantly from 59.4\% to 45.9\% during the period from 1995 to 2005. In contrast, the incidence of PU and gastric ulcer (GU) increased significantly during that same period, while that of duodenal ulcer (DU) did not significantly change, which suggests that a portion of the PU seen, was caused by NSAID or aspirin rather than $H$. pylori infection during the period of aging population. ${ }^{10} \mathrm{~A}$ recent retrospective Korean study showed that old age

Correspondence to: Yong Chan Lee

Department of Internal Medicine, Yonsei University College of Medicine, 50 Yonsei-ro, Seodaemun-gu, Seoul 03722, Korea

Tel: +82-2-2228-1960, Fax: +82-2-393-6884, E-mail: leeyc@yuhs.ac

Received on August 3, 2020. Revised on August 31, 2020. Accepted on September 4, 2020.

pISSN 1976-2283 eISSN 2005-1212 https://doi.org/10.5009/gnl20246

() This is an Open Access article distributed under the terms of the Creative Commons Attribution Non-Commercial License (http://creativecommons.org/licenses/by-nc/4.0) which permits unrestricted non-commercial use, distribution, and reproduction in any medium, provided the original work is properly cited. 
and major comorbidity were significant risk factors for NSAIDassociated PU perforation. ${ }^{11}$ In summary, drug-related PU often occurs among the elderly with comorbidities, and sometimes is expected to contribute to the development of serious complications such as bleeding and perforation. Thus, it is important to identify the clinical characteristics of drug-related PU and develop clinical practice guidelines for its appropriate treatment and prevention.

Clinical practice guidelines for drug-related PU were previously developed and published in the United States (American College of Gastroenterology), ${ }^{12}$ Canada (Canadian Association of Gastroenterology) ${ }^{13}$ and Japan (Japanese Society of Gastroenterology). ${ }^{14}$ Previously, Korean guidelines for prevention and treatment of NSAID-related PUs, ${ }^{15}$ as well as diagnosis for PU disease, ${ }^{16}$ treatment for non-bleeding PU disease, ${ }^{17}$ treatment for bleeding PU disease ${ }^{18}$ and treatment for PU disease under special conditions, ${ }^{19}$ were developed under the auspices of the Korean College of Helicobacter and Upper GI Research and the Korean Society of Gastroenterology in 2009. However, these previous guidelines were criticized for the lack of evidence produced by systematic literature review as well as multidisciplinary approach, and were closer to expert opinions rather than evidence-based clinical practice guidelines. Revised clinical practice guidelines primarily focused on the prevention and treatment of drug-related PU considering its prevalence and severity, and produced by evidence-based guideline statements based on a de novo process was needed to overcome the limitations of previous guidelines.

The main target population of this clinical practice guideline is adult patients with long-term administration of NSAIDs, aspirin or other antiplatelet agents or anticoagulants, who have a history of drug-related PU and its complications or who correspond to a high-risk group. In particular, this clinical practice guideline actively reflects the contents of questions about the selection or resumption of drugs, which were frequently asked by patients who visited the outpatient department of gastroenterology, or who had undergone inpatient treatment due to PU and its complications during the long-term administration of NSAIDs, aspirin or antiplatelet agents or anticoagulants. The purpose of this clinical practice guideline therefore, is to summarize the risk factors for drug-related PU and to provide appropriate guidelines for the prevention and treatment of drugrelated PUs and its complications in patients with long-term use of NSAIDs, aspirin or other antiplatelet agents and anticoagulants. It is to be hoped that this guideline, will help clinicians make decisions at the outpatient department of primary medical institutions. Furthermore, the authors aimed to provide specific guidelines for gastroenterologists, as well as orthopedic surgeons, rheumatologists, cardiologists, neurologists and other related specialists who frequently prescribe NSAIDs, aspirin or other antiplatelet agents, or anticoagulants, to effectively manage PU and its complications in the course of outpatient and in- patient treatment at secondary and tertiary medical institutions. The authors' intent was also to provide educational materials for medical workers such as doctors and nurses in training, and to enhance the predictability of medical services and help them choose optimal treatments by providing the best standards for clinical care. Through all of these efforts, the authors intended to improve the quality of life of patients and contribute to improving national health.

This clinical practice guideline is a specific and comprehensive recommendation for the treatment of drug-related PU. This guideline was written as evidence-based recommendations rather than a list of textbook knowledge. However, in areas of clinical significance and where expert opinions are consistent, recommendations have been made by agreement even though there was a lack of specific evidence in the literature.

\section{DEVELOPMENT PROCESS OF THE CLINICAL PRACTICE GUIDELINE}

\section{Organization of the guideline committee and multidisci- plinary team}

The clinical guideline practice committee was composed of the Steering Committee, the Development Committee and the Appraisal Committee. The Steering Committee established the strategy and direction of guidance development, appointed the relevant chairperson, and reviewed and approved the project budget. The Steering Committee also coordinated stakeholders in the development of the guideline and supervised the maintenance of editorial independence. The Development Committee was established under the Korean College of Helicobacter and Upper GI Research, and consisted of 14 gastroenterologists from 11 universities (general chairman: Yong Chan Lee; committee chairman: Byung-Wook Kim; secretary: Moon Kyung Joo; members: Beom Jin Kim, Joon Sung Kim, Jae Myung Park, Chan Hyuk Park, Chang Seok Bang, Ji Yong Ahn, Hyo-Joon Yang, Bong Eun Lee, Jeong Hoon Lee, Hye-Kyung Jung, and Yu Kyung Cho). Two methodology experts (Hyun Jung Kim and Ein Soon Shin) conducted workshops in each part of the development process of the guideline (Preparation for Revising Clinical Practice Guidelines and Systematic Literature Review [July 12, 2017] and Qualification of Literature Using Review Manager [RevMan, the Nordic Cochrane Centre, Copenhagen, Denmark; December 21, 2017]) to provide training on the methodology for developing clinical practice guidelines, and the committee developed this guideline consistent with the principles of evidence-based medicine. The Appraisal Committee consisted of three members, and two gastroenterologists who did not participate in the development of the guideline conducted peer review for external evaluation. To ensure this was a multidisciplinary process, the following academic societies participated in the development of the guideline: the Korean Society of Gastroenterology, the Korean Society of Cardiology, the Korean Society of 
Pathologists, the Korean Gastric Cancer Association, the Korean Society of Pediatric Gastroenterology, Hepatology and Nutrition, the Korean Physician's Association. Since the first meeting was held on June 14, 2017, a total of 12 committee meetings, two workshops and one off-line and one on-line Delphi vote were conducted through August 2018, to produce draft recommendations.

\section{Development process of clinical practice guideline}

The Development Committee reviewed previous Korean guidelines on the prevention and treatment of NSAID-related PU15 and other related guidelines ${ }^{16-19}$ which were developed under supervision of the Korean College of Helicobacter and Upper GI Research and the Korean Society of Gastroenterology in 2009. A decision was made to develop the guidelines to cover the treatment and prevention of drug-related PU and its complications caused by NSAID, aspirin or other antiplatelet agents or anticoagulants specifically, from among the total available information on diagnosis, treatment and prevention of PU. Furthermore, considering the criticism that previous guidelines had been closer to experts' opinions rather than evidence-based clinical practice guideline, the Development Committee proceeded with a de novo method, which newly selected key questions and drew recommendations for key questions through systematic literature review and quality assessment, and excluded individual expert opinion as much as possible.

\section{1) Selection of key questions}

The selection of key questions for the clinical practice guidelines were made primarily with the participation of all members of the Development Committee, and were finalized in consideration of external guidelines and domestic clinical practice. The key clinical questions for each subject were selected following the principle of PICO (Population, Intervention, Comparison, Outcome), and systematic literature searches were conducted on the basis of PICO (Supplementary Table 1).

\section{2) Literature search}

Literature from January 1987 to November 2017 was systemically searched using three bibliographic databases (MEDLINE, EMBASE, and Cochrane Library) and a search engine (KoreaMed). We searched the literature with a combination of population-related index words (NSAID, aspirin, antiplatelet agent, anticoagulant, and PU) and intervention-related index words (proton pump inhibitor [PPI], microprostol, histamine-2 receptor antagonist [H2RA], and $H$. pylori eradication) (Supplementary Table 2). The selection criteria applied to literature were as follows: (1) studies of adults over 18 years; and (2) original articles, and exclusion criteria were as follows: (1) editorials; (2) letters, brief reports or syllabi; (3) case reports; or (4) abstracts. The Development Committee requested web search by providing index words to a librarian who majored in literature and infor- mation science, and duplicate literature was excluded through cross-search. After initial screening of literature that did not meet the selection/exclusion criteria based on the title and abstract, the full text of the screened literature was carefully read and the literature that met the selection/exclusion criteria was finally selected. Two independent reviewers reviewed the full text, and a literature was selected if both reviewers agreed that it was corresponding to the subject. However, if the decisions did not coordinate, the final decision was made after discussion by the whole Development Committee.

\section{3) Quality assessment of literature and meta-analysis}

The selected literature was qualified by Cochrane Collaboration's Tool for Assessing the Risk of Bias if it was a randomized controlled trial (RCT), ${ }^{20}$ and by Risk of Bias Assessment tool for Non-randomized Studies (RoBANS) ${ }^{21}$ in the case of nonrandomized trial. Two reviewers evaluated the literature independently, and if there was disagreement among reviewers, the final decision was made either by discussion or by arbitration of a third party. The effect of specific interventions on the results were presented as odds ratio (OR) or relative risk (RR) with 95\% confidence interval (CI), respectively, using the RevMan (version 5.3.3) and the Comprehensive Meta-analysis Software 3.0 (Biostat, Englewood, NJ, USA) programs. The results of each metaanalysis were summarized using Forest plot, and the publication bias of the studies was evaluated by funnel plot. Heterogeneity was evaluated by $I^{2}$ test, which was calculated by the following equation: $I^{2}(\%)=100 \times(\mathrm{Q}-\mathrm{df}) / \mathrm{Q}(\mathrm{Q}=$ chi-square statistic, $\mathrm{df}=$ degree of freedom). $I^{2}$ values exist between 0 and 100\%, with a greater homogeneity at less than 25\%, a moderate degree at 50\%, and a higher degree of heterogeneity at 75\%.

\section{4) Extraction of recommendations and decisions on strength of recommendation and level of evidence}

Based on the results of meta-analysis, 11 draft recommendations were initially made; six were about NSAID, three for aspirin, two for anticoagulants. Strength of recommendation and level of evidence were decided using GRADE (Grading of Recommendations Assessment, Development and Evaluation, http://www.gradeworkinggroup.org). Strength of recommendation was classified according to 5 grades: (1) strong for; (2) weak for; (3) strong against; (4) weak against; (5) insufficient (Table 1), and level of evidence as 4 grades: (1) high; (2) moderate; (3) low; (4) very low (Table 2). Then, downgrade or upgrade of level of evidence were considered according to the following criteria: In the case of RCT, the level of evidence was downgraded one or two grades if there was (1) risk of bias; (2) inconsistency; (3) indirectness; (4) imprecision; and (5) publication bias existed; and in case of observational study, the level of evidence was upgraded one or two grades if, (1) large effect magnitude existed; (2) if dose response existed, and (3) all plausible residual confounding and bias would reduce a demonstrated effect. ${ }^{22}$ The 
Table 1. Strength of Recommendation

\begin{tabular}{|c|c|}
\hline Strength of recommendation & Interpretation \\
\hline Strong for & $\begin{array}{l}\text { The benefit of the intervention is greater than the harm and the level of evidence is high, which is strongly } \\
\text { recommended in most clinical situations. }\end{array}$ \\
\hline Weak for & $\begin{array}{l}\text { The benefit of the intervention may vary depending on the clinical situation of the intervention or the patient/ } \\
\text { social value, and is recommended to be used selectively or conditionally. }\end{array}$ \\
\hline Strong against & $\begin{array}{l}\text { The harm of the intervention is greater than the benefit and the level of evidence is high or the size of effec- } \\
\text { tiveness is unclear and the level of evidence is low, which is recommended not to be used. }\end{array}$ \\
\hline Weak against & $\begin{array}{l}\text { The harm of the intervention may vary depending on the clinical situation of the intervention or the patient/ } \\
\text { social value, and is recommended not to be used selectively or conditionally. }\end{array}$ \\
\hline Insufficient & $\begin{array}{l}\text { Evidence to judge the size of effectiveness of the intervention or the level of evidence is insufficient, and it is } \\
\text { not possible to decide whether or not to recommend until further research evidence is accumulated. }\end{array}$ \\
\hline
\end{tabular}

Table 2. Level of Evidence

\begin{tabular}{|c|c|}
\hline Quality level & Interpretation \\
\hline High & We are very confident that the true effect lies close to that of the estimate of the effect. \\
\hline Moderate & $\begin{array}{l}\text { We are moderately confident in the effect estimate. The true effect is likely to be close to the estimate of the effect, but there is a } \\
\text { possibility that it is substantially different. }\end{array}$ \\
\hline Low & Our confidence in the effect estimate is limited. The true effect may be substantially different from the estimate of the effect. \\
\hline Very low & We have very little confidence in the effect estimate. The true effect is likely to be substantially different from the estimate of effect. \\
\hline
\end{tabular}

strength of recommendation was determined by considering not only the level of evidence but also the magnitude of the effect (the balance between benefit and harm), patients' preferences and values, the use of resources, and the possibility of domestic application of the level of evidence. Members of the Development Committee decided on the wording and strength of the recommendations through face-to-face meetings or discussions via e-mail, taking into account the balance between the favorable and unfavorable outcomes of intervention, the quality of evidence, patients' values and preferences, feasibility, and benefits and risk factors.

\section{5) Agreement and acceptance of recommendations}

After draft recommendations were extracted, the Development Committee invited academic experts representing the main user population of the related drugs, and adopted the recommendations using modified Delphi method. The experts who participated as members of the panel were as follows: current and former chairmen, secretary general and director and members of Scientific Committee of the Korean College of Helicobacter and Upper GI Research, and board members representing the Korean Society of Gastroenterology, the Korean Society of Cardiology, the Korean Society of Pathologists, the Korean Gastric Cancer Association, the Korean Society of Pediatric Gastroenterology, Hepatology and Nutrition and the Korean Physician's Association. Before the vote, the panel was sent an e-mail with recommendations and supporting documents so that they could read the contents in advance and judge independently.
On the day of the vote, members of the Development Committee announced the recommendations, evidences, strength of recommendations and level of evidence, and at the end of the presentation, the panels conducted an anonymous vote using an electronic keypad. The degree of agreement on the draft recommendations was determined as follows using a 5-point Likert scale: (1) completely agree; (2) mostly agree; (3) partially agree; (4) mostly disagree; (5) completely disagree; (6) not sure. If the number of votes of agreement from combining (1) and (2) was more than two-thirds of the total number of votes cast, the recommendation was considered an agreement. Immediately after the vote on each recommendation, the panels discussed the evidence for supporting the recommendation and benefits and harms. Of the 11 recommendations, nine were adopted as a result of the first round of voting, while two were dismissed, which also failed to obtain the consent of more than two-thirds on the second round of online voting and finally were rejected. Therefore, it was decided that the nine recommendations had been finally agreed upon.

\section{6) External review}

Each member of the Development Committee in charge of each recommendation prepared a manuscript of the details by referring to the key questions, the process of extracting recommendations, the evidence within the literature and the minutes. Two experts (Gwang Ho Baik and Kee Don Choi) in the field of gastroenterology related to PUs who did not directly participate in the development, objectively verified the draft manuscript 
prepared by the Development Committee. The points identified in peer reviews were modified and reflected through the second internal discussion process. For external review by a group of experts, a draft of the clinical practice guideline, which included nine adopted and two dismissed recommendations, was presented to the 200 members of the academic society composed of specialists in gastroenterology at the 2018 annual autumn PG Course of the Korean College of Helicobacter and Upper GI Research, and opinions were collected through open discussion. The Development Committee confirmed again that it was not appropriate to adopt the two dismissed recommendations as final recommendations in this clinical practice guideline, reflecting the opinion that the studies related to the two dismissed recommendations (the preventive effect of misoprostol on longterm NSAID users; the preventive effect of H2RA on long-term NSAID users) were mostly conducted a long time ago, and that the two drugs in question were not routinely used in actual clinical practice.

\section{7) Financial support for development of the clinical prac- tice guideline and independence of development}

Although this guideline was developed on the academic society's own budget without external financial support, the Development Committee operated independently of the Korean College of Helicobacter and Upper GI Research. Furthermore, throughout the development of the guideline, funding and financial support from the academic society have not directly, indirectly, or potentially affected the content of the guideline or the process used to develop the guideline. All the members of the Development Committee were investigated as follows to ensure that they had no conflicts of interest or potential conflicts and, in fact, no conflicts of interest arose during their participation in the guidelines development: (1) if a member received more than 10 million won in sponsorship or compensation for a topic related to the development of the guideline in the past 2 years; (2) if a member has experience in conducting related research with funding from a specific institution or pharmaceutical company; (3) if the right to economic benefits, such as share interests, is provided by the agency concerned with the development of the guideline; (4) if an official or unofficial title has been provided by the agency concerned with the development of the guidelines; (5) if a member owned intellectual property rights for drugs related to the development of the guideline. The Development Committee intended to ensure confidence in the editorial independence by submitting the above in writing.

\section{8) Future plans for dissemination, distribution, and revision}

This guideline was certified by the Korean Medical Association (KMA) in June 2020 and it was included in the information center for clinical practice guideline of the KMA website (https:// www.guideline.or.kr/). In addition, the Development Committee intends to publish this guideline in the Korean Journal of
Gastroenterology and international medical journals related to gastroenterology, and to post it on the website of the associated academic society, Twitter, and Facebook so that any clinician can easily download and use it. The Development Committee also intends to register and publicize it on the website of the Korean Association of Internal Medicine, and to produce pamphlets composed of a summary of the guideline and distribute them actively through future academic events. After distribution, this clinical practice guideline will be used as a basis for the treatment and care of patients at each level of medical institutions and nursing institutions, as well as presented as a seminar on conservative education of academic organizations related to drug-related PUs, for training of human resources for health and medical workers, and dissemination of medical knowledge for patients and caregivers.

For proper supervision and evaluation of the implementation of this guideline, a survey on whether the recommendations are implemented will be conducted on members of the Korean College of Helicobacter and Upper GI Research in the future, and the results of the survey will be announced on the society's website. Furthermore, the Scientific Committee and the Research Affairs of the Korean College of Helicobacter and upper GI research will monitor the study outcomes and future foreign clinical practice guidelines related to NSAIDs, aspirin or other antiplatelet agents, or anticoagulants, and will revise this guideline every 3 to 5 years if new research results are accumulated and it is deemed necessary to add to, or change recommendations.

\section{CONSENSUS STATEMENTS}

Statement 1. High-risk factors of NSAID-induced PU and its complications include old age, a history of PU, administration of high-dose NSAIDs, and co-administration of aspirin, antiplatelet agent, or steroid. We recommend checking patients' past history and their medications to prevent PU and its complications in patients who receive NSAID medication.

Strength of recommendation: strong for, level of evidence: low Expert opinion: completely agree (74\%), mostly agree (22\%), partially agree $(0 \%)$, mostly disagree $(4 \%)$, completely disagree $(0 \%)$, not sure $(0 \%)$

The risk factors of PU and its complication in patients who receive NSAID medications have been reported in the secondary analysis of RCTs and in several observational studies. ${ }^{23-28}$ A prospective study by Laine et al. ${ }^{28}$ demonstrated that age $\geq 65$ years, a history of PU, and co-administration of low-dose aspirin (LDA) were major associated factors for PU and its complications in patients taking NSAIDs. In a retrospective cohort study by Lee et $a l .{ }^{25}$ on the risk factors of NSAID-induced gastropathy, age $\geq 60$ years was the most important risk factor. A case-control study by García Rodríguez and Jick ${ }^{24}$ identified that old age, smoking 
habit, a history of PU, and co-administration of anticoagulant or steroid, in addition to a history of PU bleeding, were risk factors of upper GI bleeding. Among the risk factors of PU bleeding, a history of PU complication was the highest risk factor (RR, 13.5; 95\% CI, 10.3 to 17.7), and followed by multiple NSAID use (RR, 9.0; 95\% CI, 5.7 to 14.2), co-administration of anticoagulant (RR, 6.4; 95\% CI, 2.8 to 14.6) and an uncomplicated PU history (RR, 6.1; 95\% CI, 5.1 to 7.3). Additionally, the risk of NSAID-induced PU bleeding increases as patients' age increases. The RR (95\% CI) for PU bleeding was 1.6 (1.4 to 2.0) in 50s, 3.1 (2.5 to 3.7) in 60s, and 5.6 (4.6 to 6.9) in 70s compared to individuals who were 25 to 49 years. ${ }^{24}$ The significant risk of old age for NSAIDinduced PU may be due to the high tendency of daily NSAID medication in older people. ${ }^{29}$

Therefore, we should know that the risk of PU and its complications are increased if patients are old, have a history of PU, or use multiple NSAIDs, aspirin, antiplatelet agent, anticoagulant, or steroid. In these cases, we also need an effort to prevent PU.

Statement 2. We recommend that patients scheduled for long-term NSAID therapy undergo testing for, and treatment of, $H$. pylori infection in order to prevent PU and its complications.

Strength of recommendation: strong for, level of evidence: high

Expert opinion: completely agree (88\%), mostly agree (0\%), partially agree (8\%), mostly disagree $(0 \%)$, completely disagree (0\%), not sure (4\%)

Benefit: preventive effect on PU and its complications

Harm: increase of antibiotic-resistant $H$. pylori strain

Six RCTs compared the effect of $H$. pylori eradication for decreasing NSAID-related PU (Supplementary Fig. 1). ${ }^{30-35}$ Overall, $H$. pylori eradication significantly reduced the occurrence of NSAID-related PU compared with non-eradication (pooled RR, 0.54; 95\% CI, 0.31 to 0.94) (Supplementary Fig. 2). However, this effect was inconsistent in subgroup analysis based on the exposure history of NSAID, and $H$. pylori eradication was more effective for decreasing PUs in NSAID-naïve patients (pooled RR, 0.27; 95\% CI, 0.14 to 0.53) (Supplementary Fig. 3), ${ }^{30-32}$ but not in chronic NSAID users (pooled RR, 0.92; 95\% CI, 0.58 to 1.46) (Supplementary Fig. 4). ${ }^{33-35}$ In addition, the effect of $H$. pylori eradication for reductions in PU-related complications was also inconsistent by exposure history of NSAID. $H$. pylori eradication significantly decrease the major complications of PU such as bleeding in NSAID-naïve patients with PU history, ${ }^{31}$ however, rebleeding rate within 6 months between the $H$. pylori eradicated group and omeprazole maintenance group without eradication among long-term naproxen users with a history of PU bleeding, was significantly higher in the eradication group than the omeprazole group (eradication group 18.8\% vs omeprazole group 4.4\%; absolute difference [95\% CI], 14.4\% [4.4 to 24.4$] ; p=0.005) .^{36}$ In summary, we recommend that patients scheduled for long-term NSAID therapy undergo testing for, and treatment of, $H$. pylori infection. However, the increasing incidence of antibiotic-resistant $H$. pylori strains is a global trend, ${ }^{37}$ and clinicians need to be careful when selecting an eradication regimen considering that amoxicillin, clarithromycin and quinolone-resistant strains are currently significantly increasing in several areas. $^{38}$

Statement 3. We recommend high-risk patients who are taking long-term NSAID medications receive low-dose PPIs to prevent PU and its complications.

Strength of recommendation: strong for, level of evidence: high Expert opinion: completely agree (78\%), mostly agree (18\%), partially agree (4\%), mostly disagree (0\%), completely disagree $(0 \%)$, not sure $(0 \%)$

Benefit: preventive effect on PU and its complications

Harm: Potential adverse events of long-term PPI use (e.g., fracture, pneumonia, Clostridioides difficile infection, electrolyte imbalance)

Nine RCTs on the preventive effect of PPI co-administration for NSAID-induced PU were identified (Supplementary Fig. 5). ${ }^{32,39-46}$ Pooled RR (95\% CI) for PU development was 0.29 (0.17 to 0.49 ) in the $<12$ weeks of NSAID use, 0.46 (0.19 to 1.14 ) in the 12-24 weeks of NSAID use, and 0.23 (0.17 to 0.49 ) in the $\geq 24$ weeks of NSAID use. In other words, co-administration of PPIs reduced the risk of PU development by 54\% to 76\% compared to use of NSAID without PPIs (Supplementary Fig. 6).

In the subgroup analysis of different doses of PPIs for PUpreventive effects, standard-dose of PPIs and low-dose (maintenance dose) of PPIs were evaluated in five and eight studies, respectively (Supplementary Fig. 7). Pooled RR (95\% CI) of standard-dose PPIs was 0.56 (0.31 to 1.00 ) and that of low-dose PPIs was 0.19 (0.12 to 0.30) (Supplementary Fig. 7). Even lowdose PPIs had a preventive effect on NSAID-induced PU. Additionally, there was no evidence that standard-dose PPIs was superior in terms of PU prevention to low-dose. In the subgroup analysis of different types of PPIs, preventive efficacy seemed to not be different across the types of PPIs, despite insufficient studies to reach a definitive conclusion (Supplementary Fig. 8).

Common adverse events of PPIs include diarrhea, nausea, vomiting, abdominal pain, and headache; however, most are mild and self-limiting. ${ }^{47}$ Nevertheless, the compliance of PPIs is low because they need to be taken before meals. ${ }^{48}$ Additionally, many observational studies have reported various adverse events associated with long-term PPI use, including fracture, ${ }^{49}$ pneumonia, ${ }^{50} \mathrm{C}$. difficile, ${ }^{51}$ electrolyte imbalance, ${ }^{52}$ renal disease, ${ }^{53}$ dementia, ${ }^{54}$ myocardial infarction, ${ }^{55}$ small intestinal bacterial overgrowth. ${ }^{56}$ In most studies, however, the level of evidence was low. The benefit of co-administration of PPIs outweighs the hazard in high-risk patients for NSAID-induced PU. ${ }^{57}$ Nevertheless, the need for long-term NSAID therapy should be 
periodically reassessed based on individual patient's clinical symptoms given the potential risk of PPIs. If discontinuation of NSAIDs is possible, or if potential adverse events such as fracture, pneumonia, $C$. difficile infection, or electrolyte imbalance occur during long-term PPI therapy, the discontinuation of PPIs should be considered.

The effect of PPIs for prevention of NSAID-induced PU has been proven through RCTs with low-risk of bias. Significant heterogeneity was identified in several studies with $\geq 24$ weeks of NSAID use; however, the preventive effect of PPIs was confirmed in all those studies. Additionally, heterogeneity was not identified in studies with $<12$ weeks of NSAID use, and those with 12-24 weeks of NSAID use. Although there are potential adverse events related to long-term PPI therapy, the beneficial effect of co-administration of PPIs is greater than the potential risks in high-risk patients for NSAID-induced PU. Taken together, we recommend that high-risk patients who are taking longterm NSAID medications receive low-dose PPIs to prevent PU and its complications. However, the comparison of preventive effects between PPI dosages was derived from subgroup metaanalysis without direct comparative studies. Additionally, dosedependent efficacy was not fully evaluated in all types of PPIs. It is difficult to conclude that the use of standard-dose PPIs is more harmful than that of low-dose PPIs. Therefore, low-dose PPIs may be considered primarily; however, standard-dose of PPIs may be used based on clinical needs.

\section{1) Preventive effect of misoprostol in patents with long- term NSAID use}

The preventive effect of misoprostol for NSAID-induced PU has been reported in 12 RCTs (Supplementary Fig. 9). ${ }^{58-69}$ Coadministration of misoprostol with NSAIDs reduced the risk of PU development by 55\% to 74\% compared to administration of NSAIDs alone (Supplementary Fig. 10). The effect size of misoprostol for the prevention of NSAID-induced PU was similar to that of PPIs. Depending on the duration of NSAIDs, the prevention effects on PU before 12 weeks, 12-24 weeks, and 24 weeks or later were reported in seven, five, and two studies, respectively. The pooled RR (95\% CI) was 0.31 (0.20 to 0.47$)$ in the $<12$ weeks, 0.26 (0.18 to 0.38 ) in the $12-24$ weeks, and 0.45 (0.26 to 0.41$)$ in the $\geq 24$ weeks of duration. There was no significant difference in the preventive effects of PUs even if the duration of administration was extended.

In the subgroup analysis of misoprostol dosage, pooled RR of 400-600 $\mu \mathrm{g}$ of misoprostol was 0.32 (95\% CI, 0.22 to 0.47) in eight studies, and that of $800 \mu \mathrm{g}$ of misoprostol was also 0.32 (95\% CI, 0.22 to 0.47 ) in five studies. There was no significant difference of preventive effect between the misoprostol dosages (Supplementary Fig. 11). Taken together, we can use misoprostol in high-risk patients who take NSAIDs who require longterm PPI therapy. However, we should consider the adverse GI events of misoprostol. In the previous meta-analysis on the efficacy and adverse events of misoprostol in NSAID users, diarrhea, abdominal pain, and nausea increased by 36\%, 36\%, and $26 \%$, respectively, compared to placebo. ${ }^{70}$ Moreover, discontinuation of misoprostol caused by adverse events increased by $41 \%$ compared to placebo. ${ }^{70}$ Considering GI adverse events and low drug compliance of misoprostol, we recommend PPIs primarily for the PU prevention. However, misoprostol can be used if it is difficult to administer PPIs.

The statement, "We recommend high-risk patients who are taking long-term NSAID medications receive 400-600 $\mu \mathrm{g}$ of misoprostol to prevent PU and its complications," formulated by the Development Committee, has not been finally adopted as a recommendation because it failed to obtain consent from more than two-thirds of the respondents in the first and second votes.

\section{2) Preventive effect of H2RA in patents with long-term NSAID use}

There were seven RCTs on the preventive effect of H2RA for NSAID-induced PU (Supplementary Fig. 12). ${ }^{71-77}$ Co-administration of H2RA with NSAIDs reduced the risk of PU development by $33 \%$ to $68 \%$ compared to administration of NSAIDs alone (Supplementary Fig. 13). Although co-administration of H2RA had a significant effect for the prevention of PU, the effect size of H2RA was relatively small compared to co-administration of PPIs or misoprostol.

Depending on the duration of NSAIDs, the prevention effects on PUs before 12 weeks, 12-24 weeks, and 24 weeks or later were reported in two, two, and five studies, respectively. The pooled RR (95\% CI) was 0.32 (0.16 to 0.64$)$ for $<12$ weeks, 0.67 (0.45 to 1.02 ) for $12-24$ weeks, and 0.51 (0.41 to 0.64 ) for $\geq 24$ weeks of duration (Supplementary Fig. 13). Although it is difficult to provide a definitive conclusion due to the limited number of studies and participants, the studies by Frank et al. ${ }^{72}$ and Hudson et al., ${ }^{76}$ that reported the preventive effect of H2RA at 2 and 4 weeks, respectively, showed large effect sizes (RR, 0.26; 95\% CI, 0.09 to 0.74 and RR, 0.37; 95\% CI, 0.15 to 0.95 , respectively), whereas other studies that reported the preventive effect at 12-24 weeks or $\geq 24$ weeks demonstrated relatively small effect sizes (12-24 weeks: RR, 0.67; 95\% CI, 0.45 to 1.02; $\geq 24$ weeks: RR, $0.51 ; 95 \%$ CI, 0.41 to 0.64$)$. These findings may imply that tachyphylaxis, which is a rapid reduction in the gastric acid-inhibitory effect of H2RA, occurs after repeated administration. In a study on the gastric acid-inhibitory effect of $20 \mathrm{mg}$ of famotidine and $20 \mathrm{mg}$ of omeprazole, the proportion with intragastric $\mathrm{pH}>4$ was $46.9 \%$ with famotidine and $44.6 \%$ with omeprazole at the first day of administration, 35.7\% with famotidine and 57.2\% with omeprazole at the third day, and 33.6\% with famotidine and 63.1\% with omeprazole at the 14 th day ${ }^{78}$ In other words, the gastric acid-inhibitory effect of famotidine rapidly diminished with time. In the review of tachyphylaxis of H2RA, tachyphylaxis occurred with most types of H2RAs within 2-14 days. ${ }^{79}$ Although one study reported that 
tachyphylaxis occurred at 4 weeks after H2RA, the study compared intragastric $\mathrm{pH}$ only between day-1 and week-4. In fact, in most cases, tachyphylaxis is thought to occur within 2 weeks. However, the gastric acid-inhibitory effect of H2RA does not completely disappear despite the tachyphylaxis, and preventive effects of H2RA for NSAID-induced PU was identified even in studies with $\geq 24$ weeks of administration. Therefore, H2RA may be considered if it is difficult to administer PPIs or misoprostol.

In a subgroup analysis of H2RA dosage, pooled RR of standard-dose of H2RA was 0.59 (95\% CI, 0.40 to 0.87) in four studies, and that of high-dose (double-dose) of H2RA was also 0.50 (95\% CI, 0.40 to 0.63 ) in five studies. There was no significant difference of preventive effect between the H2RA dosages (Supplementary Fig. 14).

The statement, "We recommend high-risk patients who are taking long-term NSAID medications receive standard-dose of H2RA to prevent PU and its complications," formulated by the Development Committee, has not been finally adopted as a recommendation. However, it failed to obtain consent from more than two-thirds of the respondents in the first and second votes.

Statement 4. In high-risk patients who are taking NSAIDs, medications should be chosen considering the risk of cardiovascular diseases. For patients with high-risk of NSAIDinduced PU and low-risk of cardiovascular diseases, we recommend cyclooxygenase-2 (COX-2) inhibitor as NSAID.

Strength of recommendation: strong for, level of evidence: high Expert opinion: completely agree (40\%), mostly agree (36\%), partially agree (16\%), mostly disagree (0\%), completely disagree (4\%), not sure (4\%)

Benefit: preventive effect on PU and its complications

Harm: Potentially increased risk of adverse cardiovascular events

Twenty-two RCTs comparing the risk of PU diseases between nonselective cyclooxygenase (COX) inhibitor and selective COX2 inhibitor have been identified (Fig. 1). ${ }^{80-101}$ Use of selective COX-2 inhibitor reduced the risk of PU development by 73\% to $80 \%$ compared to that of nonselective COX inhibitor (Fig. 2). The effect size of selective COX-2 inhibitor use was similar to that of co-administration of PPIs or misoprostol. In the subgroup analysis of medication duration, the pooled RR (95\% CI) of selective COX-2 inhibitor use was 0.17 (0.08 to 0.36 ) in studies with $<12$ weeks, 0.27 (0.23 to 0.33 ) in studies with $12-24$ weeks, and 0.25 (0.20 to 0.31 ) in studies with $\geq 24$ weeks. In other words, the PU-preventive effect of selective COX-2 inhibitor use was confirmed regardless of the duration of medication (Fig. 2).

There was one head-to-head clinical trial comparing selective COX-2 inhibitor use and co-administration of PPIs to nonselective COX inhibitor (Supplementary Fig. 15). In this study, there was no significant difference between the groups, although selective COX-2 inhibitor tended to be superior to co-administration of PPIs with nonselective COX inhibitor (hazard ratio [HR], 0.70; 95\% CI, 0.42 to 1.18) (Supplementary Fig. 16). ${ }^{102}$

The strategy of using selective COX-2 inhibitor to lower the
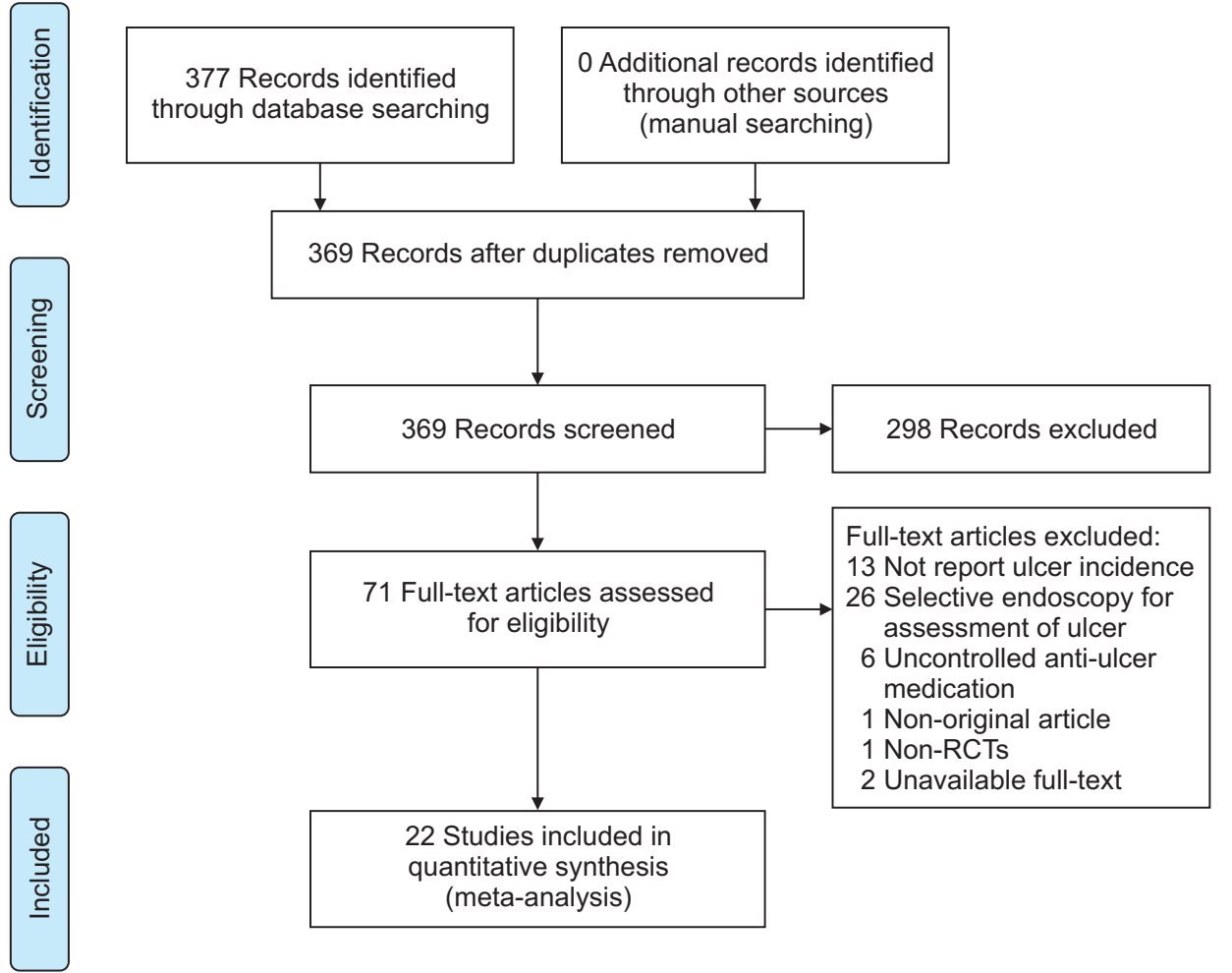

Fig. 1. Flowchart of study selection for the prevention of peptic ulcers with cyclooxygenase-2 inhibitors in NSAID users.

NSAID, nonsteroidal anti-inflammatory drug; RCT, randomized controlled trial. 


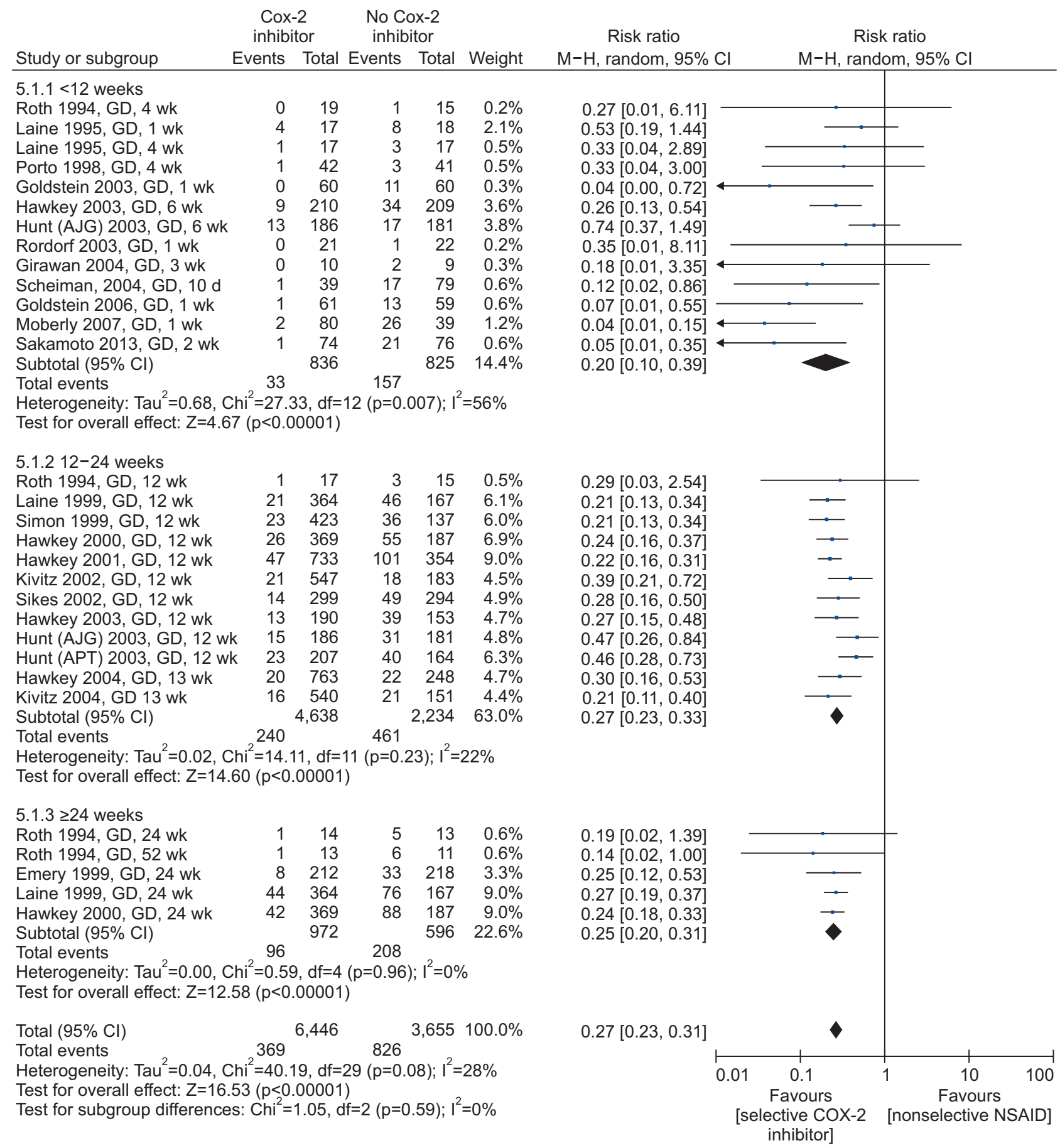

Fig. 2. The preventive effect of selective COX-2 inhibitors on gastroduodenal ulcers in long-term NSAID users. Forest plot, COX-2 versus placebo (subgroup analysis by assessment timing).

G, gastric ulcer; D, duodenal ulcer; NSAID, nonsteroidal anti-inflammatory drug; COX-2, cyclooxygenase-2; CI, confidence interval; M-H, Mantel Haenszel.

risk of PU development is advantageous compared to co-administration of PPIs or misoprostol because it can reduce the risk without additional medication. Although unspecific abdominal pain, diarrhea, and dyspepsia were reported as common adverse events of selective COX-2 inhibitor, they were mild and the adverse event-related discontinuation rate of selective COX-2 inhibitor was significantly lower than that of nonselective COX inhibitor. ${ }^{83}$ However, attention should be paid to use in patients with high-risk of cardiovascular diseases, as selective COX-2 inhibitor can increase the risk of adverse cardiovascular events. According to the meta-analysis on adverse events associated with selective COX-2 inhibitors, this drug category increased the risk of myocardial infarction by 53\% and tended to increase the risk of vascular events (RR, 1.16; 95\% CI, 0.97 to 1.36). ${ }^{103}$ 
Therefore, if patients at high-risk of NSAID-induced PU have a low risk of cardiovascular disease, selective COX-2 inhibitor can be used for prevention of PU and its complications.

The NSAID-induced PU-preventive effect of selective COX-2 inhibitor at durations of $12-24$ weeks as well as $\geq 24$ weeks has been proven in RCTs with low risk of bias. There is the potential for adverse cardiovascular events in patients with risk of cardiovascular diseases; however, for patients with low-risk of cardiovascular diseases, we strongly recommend the use of selective COX-2 inhibitor instead of nonselective COX inhibitor because its beneficial effect outweighs the harmful.

\section{1) Strategy for prevention of PU and its complications in} patients who are taking long-term NSAID

Strategies for prevention of PU and its complications in patients who are taking long-term NSAID can be determined based on the GI risk and the cardiovascular risk (Table 3). Nonselective COX inhibitor without co-administration of other drugs can be chosen for patients with low-risk of NSAID-induced PU and low-risk of cardiovascular diseases. Patients with high-risk of cardiovascular diseases even though they have no PU risk including aging, may need administration of aspirin, antiplatelet agents, or anticoagulant. Because the risk of PU or ulcer bleeding is high in those patients, they require co-administration of PPIs when NSAIDs are administered. If patients have high GI risk but low cardiovascular risk, selective COX-2 inhibitors may be chosen as NSAIDs. Co-administration of PPIs to nonselective COX inhibitor is also expected to have a similar preventive effect as a selective COX inhibitor without PPIs.

If both the GI and cardiovascular risks are high, avoid using NSAIDs if possible. However, if NSAIDs are unavoidable, it is recommended to use nonselective NSAIDs with PPIs. If it is also difficult to administer PPIs, co-administration of misoprostol to nonselective NSAIDs may be considered while paying attention to adverse GI events including diarrhea. Otherwise, co-administration of H2RA to NSAIDs may be chosen even though its PUpreventive effect is relatively low.

Statement 5. We recommend that patients who have a history of PU receiving long-term LDA therapy undergo treatment for $H$. pylori infection in order to prevent PU and its complications.

Strength of recommendation: strong for, level of evidence: low Expert opinion: completely agree (33\%), mostly agree (46\%), partially agree (21\%), mostly disagree (0\%), completely disagree $(0 \%)$, not sure $(0 \%)$

Benefit: preventive effect on PU and its complications

Harm: increase of antibiotic-resistant $H$. pylori strains

Two studies showed the effect of $H$. pylori eradication for reductions in PU and its complications (Supplementary Fig. 17), one of which was an RCT and the other a prospective cohort study. ${ }^{36,104}$ Chan et $a l .^{36}$ reported that the rebleeding rate for 6 months between an $H$. pylori eradicated group and an omeprazole maintenance group without eradication among LDA users with a history of PU bleeding, was not significantly different between the two groups (absolute difference [95\% CI], 1.0\% [ -1.9 to 3.9$] ; p>0.05)$. In a prospective cohort study, the authors recruited three cohorts of long-term LDA users (H. pylori eradicated cohort which contained $H$. pylori-positive users with PU bleeding history and H. pylori eradication; H. pylori negative cohort which contains $H$. pylori negative users with PU bleeding history; and an average cohort which contained new LDA users without PU history), and followed up ulcer bleeding for 10 years. The incidence rate ratio (IRR) of ulcer bleeding was not significantly different between $H$. pylori-eradicated cohort and

Table 3. Recommendations Regarding NSAID Use According to the Risk of NSAID-Induced Ulcer and Cardiovascular Disease

\begin{tabular}{|c|c|c|c|}
\hline & & \multicolumn{2}{|c|}{ Risk of NSAID-induced ulcer or complication } \\
\hline & & Low & High \\
\hline & & & $\begin{array}{l}\text { - Old age } \\
\text { - Peptic ulcer history } \\
\text { - Use of high dose of NSAID } \\
\text { - Concomitant use of aspirin, antiplatelet agent, antico- } \\
\quad \text { agulant, or steroid }\end{array}$ \\
\hline \multirow[t]{2}{*}{ Risk of cardiovascular disease } & Low & Use nonselective COX inhibitors & $\begin{array}{l}\text { (1) Use selective COX-2 inhibitors, or } \\
\text { (2) Add proton pump inhibitors to nonselective COX } \\
\text { inhibitors }\end{array}$ \\
\hline & High* $^{*}$ & $\begin{array}{l}\text { Add proton pump inhibitors to nonse- } \\
\text { lective COX inhibitors }\end{array}$ & $\begin{array}{l}\text { (1) Avoid NSAIDs, if possible } \\
\text { (2) Add proton pump inhibitors to nonselective COX } \\
\text { inhibitors, if NSAIDs cannot be stopped }\end{array}$ \\
\hline
\end{tabular}

NSAID, nonsteroidal anti-inflammatory drug; COX, cyclooxygenase.

${ }^{*}$ Aspirin, antiplatelet agent, or anticoagulant users for the prevention of serious cardiovascular events. 
average risk cohort, if patients take LDA only (IRR for $\mathrm{H}$. pylorieradicated cohort, 0.97 ; 95\% CI, 0.53 to 1.80 ; IRR for average risk cohort, 0.66; 95\% CI, 0.38 to 0.99). ${ }^{104}$ However, concomitant use of other antiplatelet agents or anticoagulants with LDA markedly increased the IRR in the $H$. pylori-positive cohort (IRR, 7.01; 95\% CI, 2.25 to 21.89), an effect which was reduced by co-administration of anti-ulcer drugs (IRR, 5.96; 95\% CI, 0.62 to 57.34). ${ }^{104}$ Meanwhile, an RCT showed the effect of PPI maintenance after $H$. pylori eradication. The authors recruited H. pylori-infected LDA users with a history of PU bleeding and randomized the patients after eradication as a placebo group and a lansoprazole maintenance group, and followed up for 12 months. Recurrence of ulcer complications such as bleeding was significantly lower in the lansoprazole maintenance group than the observation group (placebo group: 14.8\%, lansoprazole maintenance group: 1.6\%; adjusted HR, 10.6; 95\% CI, 1.3 to 86.1; $\mathrm{p}=0.008$ ), which showed that lansoprazole maintenance after eradication significantly reduced the recurrence of bleeding. ${ }^{105}$

In summary, $H$. pylori eradication is effective for reducing the recurrence of PU complications such as bleeding among long-term LDA users with a history of PU bleeding, however, maintenance of anti-ulcer drugs such as PPI is necessary after eradication, if patients concomitantly use drugs that can cause upper GI bleeding such as other antiplatelet agents or anticoagulants (Fig. 3). It was necessary to downgrade the level of evidence from a high level on the categories of consistency and precision, considering that the number of studies was lacking and a searched RCT could not show the superiority of eradication alone over PPI maintenance in terms of the preventive effect of rebleeding. However, the Development Committee finally decided to recommend that patients with a history of PU and bleeding receiving LDA therapy, undergo diagnosis and treatment for $H$. pylori infection, judging that on balance, the patient's benefits are greater than the harms.

Statement 6. We recommend that patients who have a history of PU receiving long-term LDA therapy are co-administered PPI to prevent PU and rebleeding.
Strength of recommendation: strong for, level of evidence: moderate

Expert opinion: completely agree (44\%), mostly agree (48\%), partially agree (4\%), mostly disagree (4\%), completely disagree $(0 \%)$, not sure $(0 \%)$

Benefit: preventive effect on PU and its complications

Harm: potential adverse events of long-term PPI use (i.e., fracture, pneumonia, $C$. difficile infection, electrolyte imbalance)

Effects of PPI on prevention of recurrent PU and its complications in patients who require long-term use of LDA (75-325 mg/ day) have been reported in a total of seven RCTs (Supplementary Fig. 18). ${ }^{105-111}$ A meta-analysis of the seven RCTs included 5,181 patients (3,112 patients with concomitant aspirin and PPI use; 2,069 patients with aspirin alone or aspirin with control drug), and the duration of treatment ranged from 12 to 72 weeks. The concomitant use of PPIs and aspirin compared with the control group reduced the occurrence PU by $83 \%$ (HR, 0.17; 95\% CI, 0.12 to $0.25 ; \mathrm{p}<0.00001$ ) (Supplementary Fig. 19A), with risk difference of -0.13 (95\% CI, -0.1 to -0.08 ; $p<0.00001$ ), and number needed to treat (NNT) of 7.7 (Supplementary Fig. 19B). In the subgroup analysis of patients with GU (Supplementary Fig. 20), DU (Supplementary Fig. 21), and ulcer bleeding (Supplementary Fig. 22), concomitant PPI and aspirin use compared with control groups reduced the incidence of GU, DU, and ulcer bleeding by $78 \%$ (HR, 0.22; 95\% CI, 0.13 to 0.35 ; $\mathrm{p}<0.00001$ ), 91\% (HR, 0.09; 95\% CI, 0.03 to 0.25; p<0.00001), and 83\% (HR, $0.17 ; 95 \% \mathrm{CI}, 0.07$ to $0.45 ; \mathrm{p}<0.0004)$, respectively, and the risk difference was -0.11 (95\% CI, -0.16 to -0.06 ; $\mathrm{p}<0.0001$, NNT of 9.1), -0.04 (95\% CI, -0.06 to $-0.02 ; \mathrm{p}<0.0001$, NNT of 25), and $-0.03(95 \% \mathrm{CI},-0.08$ to $-0.01 ; \mathrm{p}<0.10)$, respectively. In summary, PPI reduced the recurrence of PU and bleeding in patients requiring long-term use of LDA.

However, concomitant use of PPIs in all patients taking aspirin with a history of PU should be evaluated clinically, considering the benefits and risks of long-term administration. The studies included in the meta-analysis defined PUs as mucosal injuries or defects of $3 \mathrm{~mm}$ or more, suggesting that a signifi-

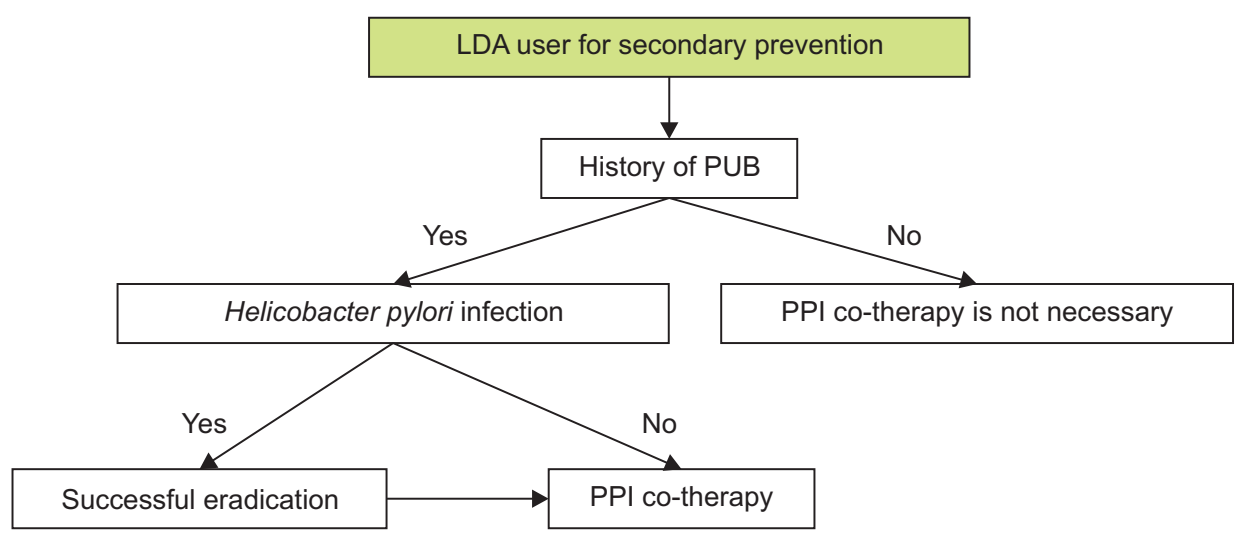

Fig. 3. Therapeutic algorithm for LDA users with a history of PUB. LDA, low-dose aspirin; PUB, peptic ulcer bleeding; PPI, proton pump inhibitor. 
cant number of patients with erosive or mild PUs that were not clinically significant were included in the study. In addition, Lai et al. ${ }^{105}$ reported that in patients who had ulcer complications associated with long-term use of LDA, the placebo group as compared with the lansoprazole group showed recurrent ulcer complications with adjusted HR of 9.6 (95\% CI, 1.2 to 76.1; $\mathrm{p}=0.008,1.6 \%$ vs $14.8 \%$ ). However, of these 10 patients with ulcer complications, four had $H$. pylori infection and two had taken NSAIDs. Therefore, in patients on long-term use of LDA with a history of PU, concomitant use of PPIs is recommended according to the severity of PU. In cases of recurrent PU or taking antiplatelet or anticoagulant drugs other than aspirin, ${ }^{104}$ it is recommended to use PPIs with the clinical judgment of the attending physician.

Statement 7. We recommend restarting aspirin as soon as possible for patients receiving aspirin for secondary cardiovascular or cerebrovascular prophylaxis, once PU bleeding has been successfully controlled with endoscopic hemostasis.

Grade of recommendation: strong, Level of evidence: moderate

Experts' opinion: completely agree (74\%), mostly agree (26\%), partially agree $(0 \%)$, mostly disagree $(0 \%)$, completely disagree $(0 \%)$, not sure $(0 \%)$

Benefit: effect on reducing major cardiovascular death Harm: risk of rebleeding

There is very limited evidence in the literature to guide proper timing of restarting antiplatelet agents in patients with PU bleeding who were taking antiplatelet agents. There was only one RCT that evaluated the risk of rebleeding and adverse cardiovascular and cerebrovascular events according to continuing or stopping aspirin in patients who were taking LDA when they developed PU bleeding (Supplementary Fig. 23). ${ }^{112}$ This study compared stopping aspirin for 8 weeks and restarting aspirin after endoscopic hemostasis in patients who were taking LDA for established cardiovascular or cerebrovascular diseases. In their findings, continuing aspirin showed a nonsignificant 2-fold increased risk of recurrent ulcer bleeding within 30 days as compared with stopping aspirin (aspirin group 10.3\% vs placebo group 5.4\%; absolute difference [95\% CI], 4.9\% points [-3.6 to 13.4]). However, continuation of aspirin significantly reduced all-cause mortality rates at 8 weeks (aspirin group 1.3\% vs placebo group 12.9\%; absolute difference [95\% CI], 11.6\% points [3.7 to 19.5]), which were mainly caused by cardiovascular, cerebrovascular, or GI events. It was necessary to downgrade the level of evidence to moderate with regard to inconsistency and imprecision because there was only one study. However, the recommendation grade was high because reduction in the risk of death and a key outcome, was significantly greater.

The Japanese Society of Gastroenterology (JSGE) and the American Society for Gastrointestinal Endoscopy (ASGE) also recommended reintroduction of aspirin immediately after hemostasis is achieved. ${ }^{14,113}$ In an exception to this, the European Society of Gastrointestinal Endoscopy (ESGE) recommended to withhold aspirin for 3 days in patients with high risk of PU bleeding (active bleeding, visible vessels, or adherent clots), ${ }^{114}$ because most recurrent bleeding with continuing aspirin developed within 3 days in the abovementioned study. ${ }^{112}$ Therefore, it is recommended that aspirin should be resumed immediately after endoscopic hemostasis in patients who need long-term maintenance of aspirin because of major cardiovascular disease.

No RCT was found to guide the timing of resumption of thienopyridine including clopidogrel or dual antiplatelet therapy following PU bleeding. Therefore, the recommendation on this was made similar to the recommendation on aspirin, an area of uncertainty which needs to be revised when further research is published in this regard (Table 4).

Statement 8. We recommend restarting anticoagulants as soon as possible for patients who need long-term anticoagulant therapy, once PU bleeding has been successfully controlled with endoscopic hemostasis. The timing for resumption is determined considering patients' risks of rebleeding and importance of resumption of anticoagulants.

Grade of recommendation: strong, Level of evidence: very low

Experts' opinion: completely agree (67\%), mostly agree (29\%), partially agree (4\%), mostly disagree (0\%), completely disagree $(0 \%)$, not sure $(0 \%)$

Benefit: effect on reducing thromboembolism and mortality

Harm: risk of rebleeding

There is little evidence on when and how to restart the anticoagulant after PU bleeding in patients taking anticoagulants,

Table 4. Recommendation Regarding Restarting Antiplatelet Agents According to the Medicine Classification

\begin{tabular}{|c|c|c|c|c|}
\hline Patents & Antiplatelet agents & Recommendation & Level of recommendation & Level of evidence \\
\hline Antiplatelet use for sec- & Aspirin & Restart after endoscopic hemostasis & Strong & High \\
\hline $\begin{array}{l}\text { ondary prophylaxis } \\
\text { of known cardiovas- }\end{array}$ & $\begin{array}{l}\text { Other agents (e.g. } \mathrm{P}_{12} \mathrm{Y}_{12} \\
\text { receptor inhibitor) }\end{array}$ & Restart after endoscopic hemostasis & Strong & Low \\
\hline cular disease & $\begin{array}{l}\text { Dual antiplatelet therapy } \\
\text { (DAPT) }\end{array}$ & $\begin{array}{l}\text { Restart aspirin after endoscopic hemostasis. } \\
\text { Early cardiology consultation for resuming } \\
\text { the second antiplatelet agent. }\end{array}$ & Strong & Low \\
\hline
\end{tabular}


and previous guidelines mentioned this issue based on expert opinion (Supplementary Fig. 24). ASGE, ${ }^{113}$ ESGE $^{114}$ and AsianPacific guideline ${ }^{115}$ recommend that resumption of anticoagulant should be made multidisciplinary access by comprehensively considering patient's status, importance of anticoagulant treatment, characteristics of hemorrhagic ulcer lesions, effective hemostasis, and risk of rebleeding. Cardiologists assess the thromboembolic risk in patients with atrial fibrillation and deep vein thrombosis, and endoscopists assess the rebleeding risk in GI tract. In principle, we recommended restarting anticoagulants immediately after effective hemostasis of ulcer in patients with PU bleeding who need long-term use of anticoagulants, if the risk of rebleeding is low.

Currently, ESGE ${ }^{114}$ and Asia-Pacific guideline ${ }^{115}$ recommend the use of vitamin $\mathrm{K}$ in patients with warfarin-related severe PU bleeding for antagonistic effects to warfarin. A previous retrospective study about the optimal timing of warfarin after endoscopic hemostasis of PU showed that rapid resumption of warfarin significantly reduced the thromboembolic risk. ${ }^{116}$ The risk of thrombosis should be assessed for each patient in order to determine the appropriate timing of resumption. Several previous retrospective studies which included patients with various thromboembolic risks ${ }^{117,118}$ showed that thrombosis and mortality were reduced without increasing the risk of rebleeding if warfarin was restarted within 7 to 30 days, however, rebleeding risk increased twice if it was started within 7 days after index bleeding. The Asian-Pacific guideline ${ }^{115}$ recommends restarting warfarin with heparin bridge therapy within 3 days of endoscopic hemostasis in high thromboembolic risk group, especially because it would take time to achieve sufficient anticoagulative effect if patients with warfarin use were given antagonists (Table 5). ${ }^{115,119,120}$ ESGE guideline ${ }^{114}$ states that resumption of warfarin should be individualized and recommends restarting warfarin between 7 to 15 days after index bleeding if possible, however, it does not mention anything with regard to heparin bridge therapy. ${ }^{114}$ Asian-Pacific guideline ${ }^{115}$ recommends intravenous administration of unfractionated heparin rather than lowmolecular-weight heparin for heparin bridge therapy, because unfractionated heparin has a short half-life (1 to 2 hours) after

Table 5. Indications for Heparin Bridging for the Temporary Discontinuation of Warfarin ${ }^{113}$

Non-valvular atrial fibrillation with a CHA2DS2-VASc score $>5^{*}$
Metallic mitral valve
Prosthetic valve with atrial fibrillation
$<3$ Months after venous thromboembolism
Severe thrombophilia (protein C or protein $S$ deficiency, antiphos-
pholipid syndrome)
"CHA2DS2-VASc, congestive heart failure ( 1 point), hypertension (1
point), age $\geq 75$ years ( 2 points), diabetes mellitus ( 1 point), stroke,
transient ischemic attack, or thromboembolism ( 2 points), vascular
disease (1 point), age $65-74$ years ( 1 point), female sex ( 1 point). ${ }^{117,118}$

intravenous administration, and it can be stopped quickly if rebleeding occurs.

The use of direct oral anticoagulants (DOAC) in patients with PU bleeding may be differently assessed based on the severity of bleeding, time taken till the last dose of DOAC, renal function and pharmacokinetic characteristics of a given drug. The AsianPacific guideline ${ }^{115}$ recommends temporally withholding the use of DOAC in patients with DOAC-related upper GI bleeding considering its short half-life. Vitamin $\mathrm{K}$ is not recommended due to absence of antagonistic effect for DOAC. Activated charcoals are considered in patients with unstable vital signs due to severe bleeding, if not more than 3 hours after taking DOAC because plasma concentrations of DOAC reach their maximum after 3 hours of administration. Idarucizumab is considered in patients with dabigatran-related severe bleeding. It is not common for patients taking DOAC to require antagonist, and clinicians can continue conservative management while waiting for the anticoagulant effect to disappear in most patients. ASGE, ${ }^{113}$ ESGE $^{114}$ and British Society of Gastroenterology (BSG) and ESGE guideline $^{121}$ does not specifically recommend the optimal timing of resumption of DOAC after endoscopic hemostasis, and Asian-Pacific guideline ${ }^{115}$ recommends restarting DOAC as soon as possible, within 3 days after discontinuation. The residual anticoagulant effect in the body decreases to a minimum within 3 days of discontinuation of DOAC due to its short half-life (12 hours) except in patients with decreased renal function. In terms of heparin bridge therapy till resumption of DOAC, Asian-Pacific guideline ${ }^{117}$ does not recommend the bridge therapy considering the rapid time of action of DOAC (1 to 4 hours), while ESGE guideline ${ }^{114}$ recommends bridge therapy with unfractionated heparin or low-molecular-weight heparin rather than immediate use of therapeutic dose of DOAC, then restarting the therapeutic dose of DOAC after disappearance of rebleeding risk.

In summary, evidence about optimal timing and method of resumption of anticoagulants in patients with PU bleeding during long-term use of anticoagulants are severely lacking, however, we recommend restarting anticoagulants as soon as possible immediately following endoscopic hemostasis of PU bleeding for patients who need long-term anticoagulant thera-

Table 6. Thrombotic Risk According to Cardiac Events ${ }^{113}$

\begin{tabular}{ll}
\hline Thrombotic risk category & \multicolumn{1}{c}{ Cardiac events } \\
\hline Very high & ACS or PCI $<6$ weeks \\
High & ACS or PCI 6 weeks to 6 months ago \\
Moderate to low & ACS or PCI $>6$ months ago; stable coronary \\
& artery disease \\
\hline
\end{tabular}

New-generation drug-eluting stents and bare-metal stents carry similar thrombotic risks. The risk is highest within the first 6 weeks after PCI. The risk remains high from 6 weeks to 6 months, then remains constant thereafter. ${ }^{120,121}$

ACS, acute coronary syndrome; PCI, percutaneous coronary intervention. 
py. The optimal timing and details of restarting are determined by comprehensively considering patients' rebleeding risk, type and pharmacokinetic characteristics of given anticoagulants, and thromboembolic risk (Table 6). ${ }^{115,122,123}$

Statement 9. We suggest high-risk patients who are taking anticoagulants to be administered PPIs to prevent upper GI hemorrhage.

Strength of recommendation: weak for, level of evidence: low Expert opinion: completely agree (38\%), mostly agree (46\%), partially agree (16\%), mostly disagree (0\%), completely disagree $(0 \%)$, not sure $(0 \%)$

Benefit: preventive effect on upper GI hemorrhage

Hazard: low drug adherence, potential adverse events of long-term PPI use (e.g., fracture, pneumonia, C. difficile infection, electrolyte imbalance)

Six nested case-control or cohort studies (three case-control $^{124-126}$ and three cohort studies ${ }^{127-129}$ ) which evaluated the protective effect of acid suppressants against anticoagulant-related GI hemorrhage were identified through the systematic review (Supplementary Fig. 25). PPI had a protective effect against upper GI hemorrhage in patients on dicumarinics (RR, 0.56; 95\% CI, 0.38 to $0.83 ; I^{2}, 0 \%$ ), which means that PPI reduced $44 \%$ of risk for the dicumarinic-related upper GI hemorrhage compared to control (Supplementary Fig. 26).

However, the H2RA did not show the same effect (RR, 0.97; 95\% CI, 0.52 to $1.81 ; I^{2}$, 0\%) (Supplementary Fig. 27). Sensitivity analysis according to the modifiers identified during systematic review also showed consistent protective effect of PPIs (RR, 0.59 ; 95\% CI, 0.37 to 0.95 ) and nonsignificant protective effect of the H2RA (RR, 0.78; 95\% CI, 0.38 to 1.64) for dicumarinicrelated upper GI hemorrhage (Supplementary Fig. 28).

Although findings in the meta-analyses suggested the protective effect of PPIs for the development of dicumarinic-related upper GI hemorrhage, this effect was attenuated by or limited due to the high baseline risk of GI injury found consistently in the enrolled studies. ${ }^{124,126,128,129}$ Moreover, less potent inhibition of gastric acid by H2RA showed a nonsignificant protective effect, suggesting that baseline ulcerogenic properties (preexistent erosion or ulcers on the upper GI tract, $H$. pylori infection, and unrecognized use of NSAIDs or aspirin) of enrolled patients determines the magnitude of the protective effect of acid suppressants on anticoagulant-related upper GI hemorrhage. In contrast to NSAIDs or aspirin, anticoagulants are not ulcerogenic drugs. Pathophysiologic evidence for anticoagulants in the development of GI hemorrhage is scarce. Therefore, the duration, dose, and adherence to PPI could not be assessed. Considering that PPIs share a common metabolic enzyme (CYP3A4), implying that their use might increase the serum concentration of warfarin, some PPIs might accelerate the absorption of warfarin, and the combination of some PPIs and the CYP2C19 intermediate metabolizer could increase bleeding events. ${ }^{130-133}$

Only two studies were included in the analysis of acid suppressants on dabigatran-related GI bleeding. ${ }^{127,128}$ It was impossible to differentiate the location of GI hemorrhage (upper vs lower) and type of acid suppressants (PPI vs H2RA). Acid suppressants did not have a protective effect against GI hemorrhage in patients on dabigatran ( $\mathrm{HR}, 0.78 ; 95 \% \mathrm{CI}, 0.44$ to $1.37 ; I^{2}$, 81.8\%) (Supplementary Fig. 29).

Interactions from co-administration of PPIs and oral factor Xa inhibitors (xabans) does not appear to be of significant concern based on previous studies. ${ }^{131,134,135}$ However, the interaction of PPIs and the direct thrombin inhibitor dabigatran was reported (low on-treatment level of dabigatran) from recently published studies. ${ }^{136-138}$ Potential adverse events related to the long-term use of PPIs is another concern. Therefore, balancing the risk-benefit approach is still necessary before the coprescription of anticoagulants and acid suppressants.

Based on the evidence above, we suggest high-risk patients who are taking anticoagulants to be administered PPIs to prevent upper GI hemorrhage. In cases with PPI and warfarin coadministration, close monitoring of prothrombin time with dose adjustment is needed. In terms of DOAC, little is known about risk and benefit of PPI co-administration. Considering the number of enrolled studies in this systematic review is small and all the studies were conducted in a retrospective manner, strength of recommendation is weak and the level of evidence is low. In the absence of randomized trials demonstrating a lack of bias, solid conclusions cannot be drawn.

\section{CONCLUSION}

The incidence of drug-related PU and its complications are expected to continue to increase due to the aging of the domestic population and the increase in prevalence of major comorbidities, which will not only seriously threaten the health of elderly patients, but also increase the mortality rate, and likely result in huge costs in medical expenses nationwide. ${ }^{139}$ Therefore, publishing and disseminating the appropriate clinical practice guidelines for patients with drug-related PU is an extremely valuable task, not only in terms of medical development but also in the pursuit of social public interest through health promotion. In the future, it will be necessary to perform additional major literature searches to better define the characteristics and optimal management of drug-related PU, and revise clinical practice guidelines to keep pace with the rapidly changing medical environment.

\section{CONFLICTS OF INTEREST}

No potential conflict of interest relevant to this article was reported. 


\section{ACKNOWLEDGEMENTS}

These guidelines are being co-published on the Gut and Liver and the Korean Journal of Gastroenterology for facilitated distribution.

We would like to express deep thanks to Manager Eun Ju Lee (Medical Library of Korea University), Doctor Myung Han Hyun (Korea University Guro Hospital), Manager Na-Jin Kim and Seung-Jae Lee (Medical Library of Catholic University Songeui Campus), who initially searched the literature by each key clinical question for systematic review; Professor Gwang Ho Baik (Department of Internal Medicine, Hallym University College of Medicine) and Kee Don Choi (Department of Internal Medicine, University of Ulsan College of Medicine), who reviewed the draft manuscript and advised through peer review, and Doctor Hyun Jung Kim (Korea University College of Medicine) and Ein Soon Shin (Research Institute for Healthcare Policy, Korean Medical Association), who gave lectures and advice at the clinic guideline workshop and reviewed and corrected the methodology of the draft recommendations.

\section{AUTHOR CONTRIBUTIONS}

Data analysis and writing - original draft: M.K.J, C.H.P., J.S.K., J.M.P., J.Y.A., B.E.L., J.H.L., H.J.Y., Y.K.C., C.S.B., B.J.K., H.K.J., B.W.K. Study design: H.K.J., B.W.K., Y.C.L. Writing - review and editing: M.K.J., C.H.P., H.K.J., B.W.K., Y.C.L. Advice on the study design: H.K.J., B.W.K., Y.C.L. Statistical support and data acquisition: H.K.J., B.W.K. All authors have read and approved the manuscript.

\section{ORCID}

Moon Kyung Joo Chan Hyuk Park https://orcid.org/0000-0001-6050-3695 Joon Sung Kim Jae Myung Park Ji Yong Ahn Bong Eun Lee Jeong Hoon Lee Hyo-Joon Yang Yu Kyung Cho Chang Seok Bang Beom Jin Kim Hye-Kyung Jung Byung-Wook Kim Yong Chan Lee

\section{REFERENCES}

1. Jhun HJ, Sung NJ, Kim SY. Knee pain and its severity in elderly Koreans: prevalence, risk factors and impact on quality of life. J
Korean Med Sci 2013;28:1807-1813.

2. Lee JH, Lim NK, Cho MC, Park HY. Epidemiology of heart failure in Korea: present and future. Korean Circ J 2016;46:658-664.

3. Shim YK, Kim N. Nonsteroidal anti-inflammatory drug and aspirin-induced peptic ulcer disease. Korean J Gastroenterol 2016;67:300-312.

4. Silverstein FE, Graham DY, Senior JR, et al. Misoprostol reduces serious gastrointestinal complications in patients with rheumatoid arthritis receiving nonsteroidal anti-inflammatory drugs: a randomized, double-blind, placebo-controlled trial. Ann Intern Med 1995;123:241-249.

5. Silverstein FE, Faich G, Goldstein JL, et al. Gastrointestinal toxicity with celecoxib vs nonsteroidal anti-inflammatory drugs for osteoarthritis and rheumatoid arthritis: the CLASS study: a randomized controlled trial. Celecoxib Long-term Arthritis Safety Study. JAMA 2000;284:1247-1255.

6. Bombardier C, Laine L, Reicin A, et al. Comparison of upper gastrointestinal toxicity of rofecoxib and naproxen in patients with rheumatoid arthritis. VIGOR Study Group. N Engl J Med 2000;343:1520-1528.

7. Schnitzer TJ, Burmester GR, Mysler E, et al. Comparison of lumiracoxib with naproxen and ibuprofen in the Therapeutic Arthritis Research and Gastrointestinal Event Trial (TARGET), reduction in ulcer complications: randomised controlled trial. Lancet 2004;364:665-674.

8. Bhatt DL, Fox KA, Hacke W, et al. Clopidogrel and aspirin versus aspirin alone for the prevention of atherothrombotic events. $\mathrm{N}$ Engl J Med 2006;354:1706-1717.

9. Moukarbel GV, Signorovitch JE, Pfeffer MA, et al. Gastrointestinal bleeding in high risk survivors of myocardial infarction: the VALIANT Trial. Eur Heart J 2009;30:2226-2232.

10. Kim JI, Kim SG, Kim N, et al. Changing prevalence of upper gastrointestinal disease in 28893 Koreans from 1995 to 2005. Eur J Gastroenterol Hepatol 2009;21:787-793.

11. Yang YJ, Bang CS, Shin SP, et al. Clinical characteristics of peptic ulcer perforation in Korea. World J Gastroenterol 2017;23:25662574.

12. Lanza FL, Chan FK, Quigley EM; Practice Parameters Committee of the American College of Gastroenterology. Guidelines for prevention of NSAID-related ulcer complications. Am J Gastroenterol 2009;104:728-738.

13. Rostom A, Moayyedi P, Hunt R; Canadian Association of Gastroenterology Consensus Group. Canadian consensus guidelines on long-term nonsteroidal anti-inflammatory drug therapy and the need for gastroprotection: benefits versus risks. Aliment Pharmacol Ther 2009;29:481-496.

14. Satoh K, Yoshino J, Akamatsu T, et al. Evidence-based clinical practice guidelines for peptic ulcer disease 2015. J Gastroenterol 2016;51:177-194.

15. Lee JH, Lee YC, Jeon SW, et al. Guidelines of prevention and treatment for NSAID-related peptic ulcers. Korean J Gastroenterol 2009;54:309-317. 
16. Kim SG, Kim JG, Shin SK, et al. Guidelines of diagnosis for peptic ulcer disease. Korean J Gastroenterol 2009;54:279-284.

17. Cheung DY, Jung HY, Song HJ, et al. Guidelines of treatment for non-bleeding peptic ulcer disease. Korean J Gastroenterol 2009;54:285-297.

18. Chung IK, Lee DH, Kim HU, et al. Guidelines of treatment for bleeding peptic ulcer disease. Korean J Gastroenterol 2009;54:298-308.

19. Kim JH, Moon JS, Jee SR, et al. Guidelines of treatment for peptic ulcer disease in special conditions. Korean J Gastroenterol 2009;54:318-327.

20. Higgins JPT, Altman DG, Sterne JAC. Chapter 8: Assessing risk of bias in included studies. In: Higgins JPT, Churchill R, Chandler J, Cumpston MS, eds. Cochrane Handbook for Systematic Reviews of Interventions (updated 2017 Jun). Cochrane, 2017. Available from: http://handbook.cochrane.org.

21. Kim SY, Park JE, Lee YJ, et al. Testing a tool for assessing the risk of bias for nonrandomized studies showed moderate reliability and promising validity. J Clin Epidemiol 2013;66:408-414.

22. Kim SY, Choi MY, Shin SS, et al. NECA's Handbook for Clinical Practice Guideline Developer version 1.0. Seoul: National Evidence-based Healthcare Collaborating Agency (NECA), 2015.

23. Shorr RI, Ray WA, Daugherty JR, Griffin MR. Concurrent use of nonsteroidal anti-inflammatory drugs and oral anticoagulants places elderly persons at high risk for hemorrhagic peptic ulcer disease. Arch Intern Med 1993;153:1665-1670.

24. García Rodríguez LA, Jick H. Risk of upper gastrointestinal bleeding and perforation associated with individual non-steroidal antiinflammatory drugs. Lancet 1994;343:769-772.

25. Lee HL, Han DS, Kim JB, et al. Importance of age and other risk factors in NSAID-induced gastropathy. Korean J Gastroenterol 2004;44:246-251.

26. Lanas A, García-Rodríguez LA, Arroyo MT, et al. Risk of upper gastrointestinal ulcer bleeding associated with selective cyclo-oxygenase-2 inhibitors, traditional non-aspirin nonsteroidal anti-inflammatory drugs, aspirin and combinations. Gut 2006;55:1731-1738.

27. Kobata Y, Yajima H, Yamao J, Tanaka Y, Fukui H, Takakura Y. Risk factors for the development of gastric mucosal lesions in rheumatoid arthritis patients receiving long-term nonsteroidal anti-inflammatory drug therapy and the efficacy of famotidine obtained from the FORCE study. Mod Rheumatol 2009;19:629636.

28. Laine L, Curtis SP, Cryer B, Kaur A, Cannon CP. Risk factors for NSAID-associated upper GI clinical events in a long-term prospective study of 34701 arthritis patients. Aliment Pharmacol Ther 2010;32:1240-1248.

29. Milder TY, Lipworth WL, Williams KM, Ritchie JE, Day RO. "It looks after me”: how older patients make decisions about analgesics for osteoarthritis. Arthritis Care Res (Hoboken) 2011;63:12801286.

30. Chan FK, Sung JJ, Chung SC, et al. Randomised trial of eradica- tion of Helicobacter pylori before non-steroidal anti-inflammatory drug therapy to prevent peptic ulcers. Lancet 1997;350:975979.

31. Chan FK, To KF, Wu JC, et al. Eradication of Helicobacter pylori and risk of peptic ulcers in patients starting long-term treatment with non-steroidal anti-inflammatory drugs: a randomised trial. Lancet 2002;359:9-13.

32. Labenz J, Blum AL, Bolten WW, et al. Primary prevention of diclofenac associated ulcers and dyspepsia by omeprazole or triple therapy in Helicobacter pylori positive patients: a randomised, double blind, placebo controlled, clinical trial. Gut 2002;51:329335.

33. Hawkey CJ, Tulassay Z, Szczepanski L, et al. Randomised controlled trial of Helicobacter pylori eradication in patients on nonsteroidal anti-inflammatory drugs: HELP NSAIDs study. Helicobacter Eradication for Lesion Prevention. Lancet 1998;352:10161021.

34. Lai KC, Lau CS, Ip WY, et al. Effect of treatment of Helicobacter pylori on the prevention of gastroduodenal ulcers in patients receiving long-term NSAIDs: a double-blind, placebo-controlled trial. Aliment Pharmacol Ther 2003;17:799-805.

35. De Leest HT, Steen KS, Lems WF, et al. Eradication of Helicobacter pylori does not reduce the incidence of gastroduodenal ulcers in patients on long-term NSAID treatment: double-blind, randomized, placebo-controlled trial. Helicobacter 2007;12:477485.

36. Chan FK, Chung SC, Suen BY, et al. Preventing recurrent upper gastrointestinal bleeding in patients with Helicobacter pylori infection who are taking low-dose aspirin or naproxen. N Engl J Med 2001;344:967-973.

37. Malfertheiner P, Megraud F, O'Morain CA, et al. Management of Helicobacter pylori infection-the Maastricht V/Florence Consensus Report. Gut 2017;66:6-30.

38. Lee JW, Kim N, Kim JM, et al. Prevalence of primary and secondary antimicrobial resistance of Helicobacter pylori in Korea from 2003 through 2012. Helicobacter 2013;18:206-214.

39. Ekström P, Carling L, Wetterhus S, et al. Prevention of peptic ulcer and dyspeptic symptoms with omeprazole in patients receiving continuous non-steroidal anti-inflammatory drug therapy: a Nordic multicentre study. Scand J Gastroenterol 1996;31:753758.

40. Bianchi Porro G, Lazzaroni M, Petrillo M, Manzionna G, Montrone F, Caruso I. Prevention of gastroduodenal damage with omeprazole in patients receiving continuous NSAIDs treatment: a double blind placebo controlled study. Ital J Gastroenterol Hepatol 1998;30:43-47.

41. Cullen D, Bardhan KD, Eisner M, et al. Primary gastroduodenal prophylaxis with omeprazole for non-steroidal anti-inflammatory drug users. Aliment Pharmacol Ther 1998;12:135-140.

42. Bianchi Porro G, Lazzaroni M, Imbesi V, Montrone F, Santagada T. Efficacy of pantoprazole in the prevention of peptic ulcers, induced by non-steroidal anti-inflammatory drugs: a prospective, 
placebo-controlled, double-blind, parallel-group study. Dig Liver Dis 2000;32:201-208.

43. Lai KC, Lam SK, Chu KM, et al. Lansoprazole reduces ulcer relapse after eradication of Helicobacter pylori in nonsteroidal antiinflammatory drug users: a randomized trial. Aliment Pharmacol Ther 2003;18:829-836.

44. Scheiman JM, Yeomans ND, Talley NJ, et al. Prevention of ulcers by esomeprazole in at-risk patients using non-selective NSAIDs and COX-2 inhibitors. Am J Gastroenterol 2006;101:701-710.

45. Desai JC, Sanyal SM, Goo T, et al. Primary prevention of adverse gastroduodenal effects from short-term use of non-steroidal antiinflammatory drugs by omeprazole $20 \mathrm{mg}$ in healthy subjects: a randomized, double-blind, placebo-controlled study. Dig Dis Sci 2008;53:2059-2065.

46. Sugano K, Kinoshita Y, Miwa H, Takeuchi T; Esomeprazole NSAID Preventive Study Group. Randomised clinical trial: esomeprazole for the prevention of nonsteroidal anti-inflammatory drug-related peptic ulcers in Japanese patients. Aliment Pharmacol Ther 2012;36:115-125.

47. Martin RM, Dunn NR, Freemantle S, Shakir S. The rates of common adverse events reported during treatment with proton pump inhibitors used in general practice in England: cohort studies. $\mathrm{Br}$ J Clin Pharmacol 2000;50:366-372.

48. Gyawali CP, Fass R. Management of gastroesophageal reflux disease. Gastroenterology 2018;154:302-318.

49. Gray SL, LaCroix AZ, Larson J, et al. Proton pump inhibitor use, hip fracture, and change in bone mineral density in postmenopausal women: results from the Women's Health Initiative. Arch Intern Med 2010;170:765-771.

50. Herzig SJ, Howell MD, Ngo LH, Marcantonio ER. Acid-suppressive medication use and the risk for hospital-acquired pneumonia. JAMA 2009;301:2120-2128.

51. Howell MD, Novack V, Grgurich P, et al. Iatrogenic gastric acid suppression and the risk of nosocomial Clostridium difficile infection. Arch Intern Med 2010;170:784-790.

52. Park CH, Kim EH, Roh YH, Kim HY, Lee SK. The association between the use of proton pump inhibitors and the risk of hypomagnesemia: a systematic review and meta-analysis. PLoS One 2014;9:e112558.

53. Sierra F, Suarez M, Rey M, Vela MF. Systematic review: proton pump inhibitor-associated acute interstitial nephritis. Aliment Pharmacol Ther 2007;26:545-553.

54. Tai SY, Chien CY, Wu DC, et al. Risk of dementia from proton pump inhibitor use in Asian population: a nationwide cohort study in Taiwan. PLoS One 2017;12:e0171006.

55. Shah NH, LePendu P, Bauer-Mehren A, et al. Proton pump inhibitor usage and the risk of myocardial infarction in the general population. PLoS One 2015;10:e0124653.

56. Lo WK, Chan WW. Proton pump inhibitor use and the risk of small intestinal bacterial overgrowth: a meta-analysis. Clin Gastroenterol Hepatol 2013;11:483-490.

57. Freedberg DE, Kim LS, Yang YX. The risks and benefits of long- term use of proton pump inhibitors: expert review and best practice advice from the American Gastroenterological Association. Gastroenterology 2017;152:706-715.

58. Bolten W, Gomes JA, Stead H, Geis GS. The gastroduodenal safety and efficacy of the fixed combination of diclofenac and misoprostol in the treatment of osteoarthritis. $\mathrm{Br} \mathrm{J}$ Rheumatol 1992;31:753-758.

59. De Melo Gomes JA. The safety of Arthrotec in patients with rheumatoid arthritis or osteoarthritis: an assessment of the upper gastrointestinal tract by endoscopy. Scand J Rheumatol Suppl 1992;96:23-31.

60. Verdickt W, Moran C, Hantzschel H, Fraga AM, Stead H, Geis GS. A double-blind comparison of the gastroduodenal safety and efficacy of diclofenac and a fixed dose combination of diclofenac and misoprostol in the treatment of rheumatoid arthritis. Scand J Rheumatol 1992;21:85-91.

61. Bardhan KD, Bjarnason I, Scott DL, et al. The prevention and healing of acute non-steroidal anti-inflammatory drug-associated gastroduodenal mucosal damage by misoprostol. Br J Rheumatol 1993;32:990-995.

62. Graham DY, White RH, Moreland LW, et al. Duodenal and gastric ulcer prevention with misoprostol in arthritis patients taking NSAIDs. Misoprostol Study Group. Ann Intern Med 1993;119:257-262.

63. Henriksson K, Uribe A, Sandstedt B, Nord CE. Helicobacter pylori infection, $\mathrm{ABO}$ blood group, and effect of misoprostol on gastroduodenal mucosa in NSAID-treated patients with rheumatoid arthritis. Dig Dis Sci 1993;38:1688-1696.

64. Melo Gomes JA, Roth SH, Zeeh J, Bruyn GA, Woods EM, Geis GS. Double-blind comparison of efficacy and gastroduodenal safety of diclofenac/misoprostol, piroxicam, and naproxen in the treatment of osteoarthritis. Ann Rheum Dis 1993;52:881-885.

65. Roth SH, Tindall EA, Jain AK, et al. A controlled study comparing the effects of nabumetone, ibuprofen, and ibuprofen plus misoprostol on the upper gastrointestinal tract mucosa. Arch Intern Med 1993;153:2565-2571.

66. Agrawal NM, Van Kerckhove HE, Erhardt LJ, Geis GS. Misoprostol coadministered with diclofenac for prevention of gastroduodenal ulcers: a one-year study. Dig Dis Sci 1995;40:1125-1131.

67. Piette F, Teillet L, Naudin R, Boichut D, Capron MH. Efficacy of misoprostol in the prophylaxis of gastroduodenal lesions induced by short-term nonsteroidal antiinflammatory drug therapy in elderly patients: a multicenter double-blind, placebo-controlled trial. Rev Rhum Engl Ed 1997;64:259-266.

68. Bocanegra TS, Weaver AL, Tindall EA, et al. Diclofenac/misoprostol compared with diclofenac in the treatment of osteoarthritis of the knee or hip: a randomized, placebo controlled trial. Arthrotec Osteoarthritis Study Group. J Rheumatol 1998;25:1602-1611.

69. Agrawal NM, Caldwell J, Kivitz AJ, et al. Comparison of the upper gastrointestinal safety of Arthrotec 75 and nabumetone in osteoarthritis patients at high risk for developing nonsteroidal anti-inflammatory drug-induced gastrointestinal ulcers. Clin Ther 
$1999 ; 21: 659-674$

70. Rostom A, Dube C, Wells G, et al. Prevention of NSAIDinduced gastroduodenal ulcers. Cochrane Database Syst Rev 2002;(4):CD002296.

71. Roth SH, Bennett RE, Mitchell CS, Hartman RJ. Cimetidine therapy in nonsteroidal anti-inflammatory drug gastropathy. Doubleblind long-term evaluation. Arch Intern Med 1987;147:17981801.

72. Frank WO, Wallin BA, Berkowitz JM, et al. Reduction of indomethacin induced gastroduodenal mucosal injury and gastrointestinal symptoms with cimetidine in normal subjects. J Rheumatol 1989;16:1249-1252.

73. Levine LR, Cloud ML, Enas NH. Nizatidine prevents peptic ulceration in high-risk patients taking nonsteroidal anti-inflammatory drugs. Arch Intern Med 1993;153:2449-2454.

74. Taha AS, Hudson N, Hawkey CJ, et al. Famotidine for the prevention of gastric and duodenal ulcers caused by nonsteroidal antiinflammatory drugs. N Engl J Med 1996;334:1435-1439.

75. Ten Wolde S, Dijkmans BA, Janssen M, Hermans J, Lamers CB. High-dose ranitidine for the prevention of recurrent peptic ulcer disease in rheumatoid arthritis patients taking NSAIDs. Aliment Pharmacol Ther 1996;10:347-351.

76. Hudson N, Taha AS, Russell RI, et al. Famotidine for healing and maintenance in nonsteroidal anti-inflammatory drug-associated gastroduodenal ulceration. Gastroenterology 1997;112:18171822.

77. Laine L, Kivitz AJ, Bello AE, Grahn AY, Schiff MH, Taha AS. Double-blind randomized trials of single-tablet ibuprofen/highdose famotidine vs. ibuprofen alone for reduction of gastric and duodenal ulcers. Am J Gastroenterol 2012;107:379-386.

78. Miner PB Jr, Allgood LD, Grender JM. Comparison of gastric $\mathrm{pH}$ with omeprazole magnesium $20.6 \mathrm{mg}$ (Prilosec OTC) o.m. famotidine $10 \mathrm{mg}$ (Pepcid AC) b.d. and famotidine $20 \mathrm{mg}$ b.d. over 14 days of treatment. Aliment Pharmacol Ther 2007;25:103-109.

79. McRorie JW, Kirby JA, Miner PB. Histamine2-receptor antagonists: rapid development of tachyphylaxis with repeat dosing. World J Gastrointest Pharmacol Ther 2014;5:57-62.

80. Laine L, Sloane R, Ferretti M, Cominelli F. A randomized doubleblind comparison of placebo, etodolac, and naproxen on gastrointestinal injury and prostaglandin production. Gastrointest Endosc 1995;42:428-433.

81. Roth SH, Bennett R, Caldron P, Mitchell C, Swenson C, Koepp R. A longterm endoscopic evaluation of patients with arthritis treated with nabumetone vs naproxen. J Rheumatol 1994;21:11181123.

82. Porto A, Reis C, Perdigoto R, Gonçalves M, Freitas P, Macciocchi A. Gastroduodenal tolerability of nimesulide and diclofenac in patients with osteoarthritis. Curr Ther Res 1998;59:654-665.

83. Emery P, Zeidler H, Kvien TK, et al. Celecoxib versus diclofenac in long-term management of rheumatoid arthritis: randomised double-blind comparison. Lancet 1999;354:2106-2111.

84. Laine L, Harper S, Simon T, et al. A randomized trial comparing the effect of rofecoxib, a cyclooxygenase 2-specific inhibitor, with that of ibuprofen on the gastroduodenal mucosa of patients with osteoarthritis. Rofecoxib Osteoarthritis Endoscopy Study Group. Gastroenterology 1999;117:776-783.

85. Simon LS, Weaver AL, Graham DY, et al. Anti-inflammatory and upper gastrointestinal effects of celecoxib in rheumatoid arthritis: a randomized controlled trial. JAMA 1999;282:1921-1928.

86. Hawkey C, Laine L, Simon T, et al. Comparison of the effect of rofecoxib (a cyclooxygenase 2 inhibitor), ibuprofen, and placebo on the gastroduodenal mucosa of patients with osteoarthritis: a randomized, double-blind, placebo-controlled trial. The Rofecoxib Osteoarthritis Endoscopy Multinational Study Group. Arthritis Rheum 2000;43:370-377.

87. Hawkey CJ, Laine L, Harper SE, et al. Influence of risk factors on endoscopic and clinical ulcers in patients taking rofecoxib or ibuprofen in two randomized controlled trials. Aliment Pharmacol Ther 2001;15:1593-1601.

88. Kivitz A, Eisen G, Zhao WW, Bevirt T, Recker DP. Randomized placebo-controlled trial comparing efficacy and safety of valdecoxib with naproxen in patients with osteoarthritis. J Fam Pract 2002;51:530-537.

89. Sikes DH, Agrawal NM, Zhao WW, Kent JD, Recker DP, Verburg $\mathrm{KM}$. Incidence of gastroduodenal ulcers associated with valdecoxib compared with that of ibuprofen and diclofenac in patients with osteoarthritis. Eur J Gastroenterol Hepatol 2002;14:11011111.

90. Goldstein JL, Kivitz AJ, Verburg KM, Recker DP, Palmer RC, Kent JD. A comparison of the upper gastrointestinal mucosal effects of valdecoxib, naproxen and placebo in healthy elderly subjects. Aliment Pharmacol Ther 2003;18:125-132.

91. Hawkey CJ, Laine L, Simon T, et al. Incidence of gastroduodenal ulcers in patients with rheumatoid arthritis after 12 weeks of rofecoxib, naproxen, or placebo: a multicentre, randomised, double blind study. Gut 2003;52:820-826.

92. Hunt RH, Harper S, Watson DJ, et al. The gastrointestinal safety of the COX-2 selective inhibitor etoricoxib assessed by both endoscopy and analysis of upper gastrointestinal events. Am J Gastroenterol 2003;98:1725-1733.

93. Hunt RH, Harper S, Callegari P, et al. Complementary studies of the gastrointestinal safety of the cyclo-oxygenase-2-selective inhibitor etoricoxib. Aliment Pharmacol Ther 2003;17:201-210.

94. Rordorf C, Kellett N, Mair S, et al. Gastroduodenal tolerability of lumiracoxib vs placebo and naproxen: a pilot endoscopic study in healthy male subjects. Aliment Pharmacol Ther 2003;18:533541.

95. Girawan D, Abdurachman SA, Djumhana A, Roslia J, Pramudiyo R. Comparison of endoscopic gastric mucosa features after administration of piroxicam to meloxicam and their correlation with dyspepsia symptoms in elderly patient with knee osteoarthritis. Acta Med Indones 2004;36:202-206.

96. Hawkey CC, Svoboda P, Fiedorowicz-Fabrycy IF, et al. Gastroduodenal safety and tolerability of lumiracoxib compared with 
Ibuprofen and celecoxib in patients with osteoarthritis. J Rheumatol 2004;31:1804-1810.

97. Kivitz AJ, Nayiager S, Schimansky T, Gimona A, Thurston HJ, Hawkey C. Reduced incidence of gastroduodenal ulcers associated with lumiracoxib compared with ibuprofen in patients with rheumatoid arthritis. Aliment Pharmacol Ther 2004;19:11891198.

98. Scheiman JM, Cryer B, Kimmey MB, Rothstein RI, Riff DS, Wolfe MM. A randomized, controlled comparison of ibuprofen at the maximal over-the-counter dose compared with prescription-dose celecoxib on upper gastrointestinal mucosal injury. Clin Gastroenterol Hepatol 2004;2:290-295.

99. Goldstein JL, Aisenberg J, Lanza F, et al. A multicenter, randomized, double-blind, active-comparator, placebo-controlled, parallel-group comparison of the incidence of endoscopic gastric and duodenal ulcer rates with valdecoxib or naproxen in healthy subjects aged 65 to 75 years. Clin Ther 2006;28:340-351.

100. Moberly JB, Harris SI, Riff DS, et al. A randomized, double-blind, one-week study comparing effects of a novel COX-2 inhibitor and naproxen on the gastric mucosa. Dig Dis Sci 2007;52:442450.

101. Sakamoto C, Kawai T, Nakamura S, Sugioka T, Tabira J. Comparison of gastroduodenal ulcer incidence in healthy Japanese subjects taking celecoxib or loxoprofen evaluated by endoscopy: a placebo-controlled, double-blind 2-week study. Aliment Pharmacol Ther 2013;37:346-354.

102. Chan FK, Hung LC, Suen BY, et al. Celecoxib versus diclofenac plus omeprazole in high-risk arthritis patients: results of a randomized double-blind trial. Gastroenterology 2004;127:10381043.

103. Farkouh ME, Greenberg BP. An evidence-based review of the cardiovascular risks of nonsteroidal anti-inflammatory drugs. Am J Cardiol 2009;103:1227-1237.

104. Chan FK, Ching JY, Suen BY, Tse YK, Wu JC, Sung JJ. Effects of Helicobacter pylori infection on long-term risk of peptic ulcer bleeding in low-dose aspirin users. Gastroenterology 2013;144:528-535.

105. Lai KC, Lam SK, Chu KM, et al. Lansoprazole for the prevention of recurrences of ulcer complications from long-term low-dose aspirin use. N Engl J Med 2002;346:2033-2038.

106. Sugano K, Matsumoto Y, Itabashi T, et al. Lansoprazole for secondary prevention of gastric or duodenal ulcers associated with long-term low-dose aspirin therapy: results of a prospective, multicenter, double-blind, randomized, double-dummy, activecontrolled trial. J Gastroenterol 2011;46:724-735.

107. Scheiman JM, Devereaux PJ, Herlitz J, et al. Prevention of peptic ulcers with esomeprazole in patients at risk of ulcer development treated with low-dose acetylsalicylic acid: a randomised, controlled trial (OBERON). Heart 2011;97:797-802.

108. Sanuki T, Fujita T, Kutsumi H, et al. Rabeprazole reduces the recurrence risk of peptic ulcers associated with low-dose aspirin in patients with cardiovascular or cerebrovascular disease: a prospective randomized active-controlled trial. J Gastroenterol 2012;47:1186-1197.

109. Sugano K, Choi MG, Lin JT, et al. Multinational, double-blind, randomised, placebo-controlled, prospective study of esomeprazole in the prevention of recurrent peptic ulcer in low-dose acetylsalicylic acid users: the LAVENDER study. Gut 2014;63:10611068.

110. Whellan DJ, Goldstein JL, Cryer BL, et al. PA32540 (a coordinated-delivery tablet of enteric-coated aspirin $325 \mathrm{mg}$ and immediate-release omeprazole $40 \mathrm{mg}$ ) versus enteric-coated aspirin $325 \mathrm{mg}$ alone in subjects at risk for aspirin-associated gastric ulcers: results of two 6-month, phase 3 studies. Am Heart J 2014;168:495-502.

111. Iwakiri R, Higuchi K, Kato M, et al. Randomised clinical trial: prevention of recurrence of peptic ulcers by rabeprazole in patients taking low-dose aspirin. Aliment Pharmacol Ther 2014;40:780795.

112. Sung JJ, Lau JY, Ching JY, et al. Continuation of low-dose aspirin therapy in peptic ulcer bleeding: a randomized trial. Ann Intern Med 2010;152:1-9.

113. ASGE Standards of Practice Committee, Acosta RD, Abraham NS, et al. The management of antithrombotic agents for patients undergoing GI endoscopy. Gastrointest Endosc 2016;83:3-16.

114. Gralnek IM, Dumonceau JM, Kuipers EJ, et al. Diagnosis and management of nonvariceal upper gastrointestinal hemorrhage: European Society of Gastrointestinal Endoscopy (ESGE) Guideline. Endoscopy 2015;47:a1-a46.

115. Chan FK, Goh KL, Reddy N, et al. Management of patients on antithrombotic agents undergoing emergency and elective endoscopy: joint Asian Pacific Association of Gastroenterology (APAGE) and Asian Pacific Society for Digestive Endoscopy (APSDE) practice guidelines. Gut 2018;67:405-417.

116. Witt DM, Delate T, Garcia DA, et al. Risk of thromboembolism, recurrent hemorrhage, and death after warfarin therapy interruption for gastrointestinal tract bleeding. Arch Intern Med 2012;172:1484-1491.

117. Lee JK, Kang HW, Kim SG, Kim JS, Jung HC. Risks related with withholding and resuming anticoagulation in patients with nonvariceal upper gastrointestinal bleeding while on warfarin therapy. Int J Clin Pract 2012;66:64-68.

118. Qureshi W, Mittal C, Patsias I, et al. Restarting anticoagulation and outcomes after major gastrointestinal bleeding in atrial fibrillation. Am J Cardiol 2014;113:662-668.

119. Antithrombotic Trialists' (ATT) Collaboration, Baigent C, Blackwell L, et al. Aspirin in the primary and secondary prevention of vascular disease: collaborative meta-analysis of individual participant data from randomised trials. Lancet 2009;373:18491860.

120. Pearce LA, Hart RG, Halperin JL. Assessment of three schemes for stratifying stroke risk in patients with nonvalvular atrial fibrillation. Am J Med 2000;109:45-51.

121. Veitch AM, Vanbiervliet G, Gershlick AH, et al. Endoscopy in 
patients on antiplatelet or anticoagulant therapy, including direct oral anticoagulants: British Society of Gastroenterology (BSG) and European Society of Gastrointestinal Endoscopy (ESGE) guidelines. Endoscopy 2016;48:c1.

122. Douketis JD, Spyropoulos AC, Spencer FA, et al. Perioperative management of antithrombotic therapy: Antithrombotic Therapy and Prevention of Thrombosis, 9th ed: American College of Chest Physicians Evidence-Based Clinical Practice Guidelines. Chest 2012;141(2 Suppl):e326S-e350S.

123. Hawn MT, Graham LA, Richman JS, Itani KM, Henderson WG, Maddox TM. Risk of major adverse cardiac events following noncardiac surgery in patients with coronary stents. JAMA 2013;310:1462-1472.

124. Lanas A, García-Rodríguez LA, Arroyo MT, et al. Effect of antisecretory drugs and nitrates on the risk of ulcer bleeding associated with nonsteroidal anti-inflammatory drugs, antiplatelet agents, and anticoagulants. Am J Gastroenterol 2007;102:507-515.

125. Massó González EL, García Rodríguez LA. Proton pump inhibitors reduce the long-term risk of recurrent upper gastrointestinal bleeding: an observational study. Aliment Pharmacol Ther 2008;28:629-637.

126. Lin KJ, Hernández-Díaz S, García Rodríguez LA. Acid suppressants reduce risk of gastrointestinal bleeding in patients on antithrombotic or anti-inflammatory therapy. Gastroenterology 2011;141:71-79.

127. Lauffenburger JC, Rhoney DH, Farley JF, Gehi AK, Fang G. Predictors of gastrointestinal bleeding among patients with atrial fibrillation after initiating dabigatran therapy. Pharmacotherapy 2015;35:560-568.

128. Chan EW, Lau WC, Leung WK, et al. Prevention of dabigatranrelated gastrointestinal bleeding with gastroprotective agents: a population-based study. Gastroenterology 2015;149:586-595.

129. Ray WA, Chung CP, Murray KT, et al. Association of proton pump inhibitors with reduced risk of warfarin-related serious up- per gastrointestinal bleeding. Gastroenterology 2016;151:11051112.

130. Sugano K. How do we manage serious gastrointestinal adverse events associated with anti-thrombotic therapy? Expert Rev Gastroenterol Hepatol 2015;9:5-8.

131. Agewall S, Cattaneo M, Collet JP, et al. Expert position paper on the use of proton pump inhibitors in patients with cardiovascular disease and antithrombotic therapy. Eur Heart J 2013;34:17081713.

132. Teichert M, Van Noord C, Uitterlinden AG, et al. Proton pump inhibitors and the risk of overanticoagulation during acenocoumarol maintenance treatment. Br J Haematol 2011;153:379-385.

133. Hata M, Shiono M, Akiyama K, et al. Incidence of drug interaction when using proton pump inhibitor and warfarin according to cytochrome P450 2C19 (CYP2C19) genotype in Japanese. Thorac Cardiovasc Surg 2015;63:45-50.

134. EINSTEIN Investigators, Bauersachs R, Berkowitz SD, et al. Oral rivaroxaban for symptomatic venous thromboembolism. $\mathrm{N}$ Engl $\mathrm{J}$ Med 2010;363:2499-2510.

135. Granger CB, Alexander JH, McMurray JJ, et al. Apixaban versus warfarin in patients with atrial fibrillation. N Engl J Med 2011;365:981-992.

136. Kuwayama T, Osanai H, Ajioka M, et al. Influence of proton pump inhibitors on blood dabigatran concentrations in Japanese patients with non-valvular atrial fibrillation. J Arrhythm 2017;33:619-623.

137. Bolek T, Samoš M, Stančiaková L, et al. The impact of proton pump inhibition on dabigatran levels in patients with atrial fibrillation. Am J Ther 2019;26:e308-e313.

138. Bolek T, Samoš M, Škorčová I, et al. Proton pump inhibition in patients treated with novel antithrombotic drugs: should we worry about thrombosis? J Cardiovasc Pharmacol 2018;72:71-76.

139. Hyun KR, Kang S, Lee S. Population aging and healthcare expenditure in Korea. Health Econ 2016;25:1239-1251. 